Article

\title{
Impact of Alternatively Polyadenylated Isoforms of ETHYLENE RESPONSE FACTOR4 with Activator and Repressor Function on Senescence in Arabidopsis thaliana L.
}

\author{
Lena Riester, Siliya Köster-Hofmann, Jasmin Doll, Kenneth W. Berendzen (D) \\ and Ulrike Zentgraf* \\ Center for Plant Molecular Biology (ZMBP), University of Tuebingen, 72076 Tuebingen, Germany; \\ lena.riester@zmbp.uni-tuebingen.de (L.R.); hofmann@uni-tuebingen.de (S.K.-H.); \\ jasmin.doll@zmbp.uni-tuebingen.de (J.D.); kenneth.berendzen@zmbp.uni-tuebingen.de (K.W.B.) \\ * Correspondence: ulrike.zentgraf@zmbp.uni-tuebingen.de
}

Received: 19 December 2018; Accepted: 22 January 2019; Published: 28 January 2019

\begin{abstract}
Leaf senescence is highly regulated by transcriptional reprogramming, implying an important role for transcriptional regulators. ETHYLENE RESPONSE FACTOR4 (ERF4) was shown to be involved in senescence regulation and to exist in two different isoforms due to alternative polyadenylation of its pre-mRNA. One of these isoforms, ERF4-R, contains an ERF-associated amphiphilic repression (EAR) motif and acts as repressor, whereas the other form, ERF4-A, is lacking this motif and acts as activator. Here, we analyzed the impact of these isoforms on senescence. Both isoforms were able to complement the delayed senescence phenotype of the erf4 mutant with a tendency of ERF4-A for a slightly better complementation. However, overexpression led to accelerated senescence of 35S:ERF4-R plants but not of 35S:ERF4- $A$ plants. We identified CATALASE3 (CAT3) as direct target gene of ERF4 in a yeast-one-hybrid screen. Both isoforms directly bind to the CAT3 promoter but have antagonistic effects on gene expression. The ratio of ERF4- $A$ to ERF4-R mRNA changed during development, leading to a complex age-dependent regulation of CAT3 activity. The RNA-binding protein FPA shifted the R/A-ratio and fpa mutants are pointing towards a role of alternative polyadenylation regulators in senescence.
\end{abstract}

Keywords: Alternative polyadenylation; ETHYLENE RESPONSE FACTOR4; senescence regulation; CATALASE3; FPA; Arabidopsis

\section{Introduction}

At the end of their development, plants lose their photosynthetic capacity and finally shed their leaves. To avoid an uneconomic loss of stored energy, minerals and nutrients through leaf abscission, the leaves undergo leaf senescence before they die. During this process, plants recycle resources and nutrients by relocating them to developing organs. It is a dynamic and highly regulated process driven by a complex genetically encoded program. However, under stress conditions, senescence is induced prematurely as an exit strategy. Therefore, this program requires a high plasticity through constantly integrating endogenous and exogenous signals. Molecules such as plant hormones, nitrogen and sugar compounds, calcium, reactive oxygen species (ROS) and most likely further substances mediate signal transduction [1-5].

In general, ROS act as signaling molecules at their site of production due to their short half-life. Among all ROS, hydrogen peroxide $\left(\mathrm{H}_{2} \mathrm{O}_{2}\right)$ is most likely the signaling molecule with the broadest reach, since it is more stable than other ROS and it can pass membranes [6]. Hydrogen peroxide 
is involved in many signal transduction pathways spanning from biotic to abiotic stress responses, but also participates in the regulation of senescence processes. The onset of senescence coincides with an increase of intracellular $\mathrm{H}_{2} \mathrm{O}_{2}$ levels as a result of a coordinated regulation of the $\mathrm{H}_{2} \mathrm{O}_{2}$ scavenging enzymes catalase and ascorbate peroxidase [7,8]. Many senescence-associated genes and transcription factors are upregulated by ROS. Differential gene expression plays an important role in the coordination of leaf senescence onset and progression [9-12]. Breeze and coworkers [12] suggested that the temporal expression and activation of transcription factors (TFs) is a crucial aspect in the course of leaf senescence. Among others, several members of the APETALA2/ETHYLENE RESPONSE FACTOR (AP2/ERFs) family are regulated in a senescence-dependent manner [9,11,12]. AP2/ERFs form a superfamily of $147 \mathrm{TF}$ genes in Arabidopsis [13,14]. Up to now, a number of AP2/ERFs have been reported to be involved in stress responses and developmental processes [15]. Some AP2/ ERF TFs are involved in the responses to components of stress signal transduction pathways, such as ROS, ethylene, jasmonic acid (JA), abscisic acid (ABA) and cytokinin, all of which are also important molecules in senescence-associated signaling [14,16]. During leaf senescence, RELATED TP ABI3/ VP1 (RAV1) and C-REPEAT / DEHYDRATION RESPONSIBLE ELEMENT BINDING FACTOR 2 (CBF2) have been reported to be positive and negative regulators, respectively. Moreover, Koyama et al. [17] have shown that ERF4 (At3g15210) and ERF8 (At1g53170) act together as positive regulators of leaf senescence by suppressing the expression of its direct target gene EPITHIOSPECIFIER PROTEIN/ EPITHIOSPECIFYING SENESCENCE REGULATOR (ESP/ESR) (At1g54040). This protein is a negative regulator of the transcription factor WKRY53 (At4g23810), a positive regulator of leaf senescence [18,19]. WRKY53 turns out to be a central node of a complex regulatory network of leaf senescence and to underlie a tight multi-layer control of expression, activity and protein stability [20-23]. In addition, ERF4 can up-regulate intracellular ROS production, as overexpression of ERF4 led to higher ROS levels, visualized by Trypan blue and DAB (3,3-diaminobenzidine)-staining [17]. In contrast, erf4/erf8 double-mutant plants produce fewer amounts of ROS during dark-induced senescence, indicating that ERF4 and/or 8 are themselves involved in regulating intracellular ROS contents [17].

The Arabidopsis ERF4 belongs to the ERF subfamily containing 122 genes. They only possess one AP2/ERF domain, which is their distinguishing feature [13,14]. They can be further classified into 12 subgroups based on further conserved amino acid motifs [14]. AtERF4 is a member of the group VIIIa ERFs, characterized by the ERF-associated amphiphilic repression (EAR) motif. This motif allows them to act as transcriptional repressors. They can repress target gene transcription even in the presence of ERF activators in transient reporter gene assays [24-26]. However, due to alternative polyadenylation and splicing, ERF4 exists in two different protein isoforms, one containing the EAR-motif (ERF4-R), one lacking it (ERF4-A) [27]. Formation of the ERF4-A isoform was shown to be induced by flg22 treatment, a bacterial peptide derived from flagellin, which induces PAMP-triggered immunity and a ROS burst. The plant RNA-binding protein FPA (At2g43410) can inhibit the formation of the ERF4-A isoform and the ROS burst. The ability of ERF4 to switch from a repressor to an activator by alternative splicing and polyadenylation adds an extra layer of complexity to molecular mechanisms underlying the ERF-mediated gene regulation [27].

Alternative splicing (AS) is an important factor in gene regulation. Many transcription factor genes undergo this process, which results in the production of multiple proteins from one single gene [28-31]. It is involved in a variety of plant growth and developmental processes, such as induction of flowering [32], plant responses to changing environmental conditions and pathogen attacks [28]. However, AS in leaf senescence has so far not been studied in detail. This study aims to analyze the role of alternative splicing and polyadenylation of ERF4 in leaf senescence. By complementation of the erf4 mutant plants with both isoforms, we provide evidence that both ERF4 isoforms function in senescence. ERF4-A acts as transcriptional activator and ERF4-R as repressor of their direct target gene CATALASE3 (CAT3), which we could identify in a yeast-one-hybrid (Y1H) screen. Catalase proteins are important enzymes in catalyzing the decomposition of $\mathrm{H}_{2} \mathrm{O}_{2}$ to water $\left(\mathrm{H}_{2} \mathrm{O}\right)$ and oxygen $\left(\mathrm{O}_{2}\right)$ and controlling the concentrations of ROS in cells [33,34]. All three Arabidopsis catalases are regulated in 
a senescence-associated manner $[7,8]$ and $\mathrm{H}_{2} \mathrm{O}_{2}$ is used as signaling molecule in senescence. Moreover, we could show that the ratio of ERF4-A and ERF4-R expression changes over development and is influenced by the RNA-binding protein FPA. A complex pattern of activating and repressing activities on CAT3 function became obvious in the erf4 mutant plants. We provide a model on how the interplay of the different components might be organized.

\section{Material and Methods}

\subsection{Yeast-One-Hybrid System}

The Matchmaker yeast-one-hybrid library screening system (ClonTech, Heidelberg, Germany) was used to screen for genes that bind to fragments of the CAT3 promoter. A 150-bp fragment (pos. -182 to -332) upstream of the linear reporter plasmid was integrated into Saccharomyces cerevisiae strain Y187 by recombination. The yeast strain with the integrated $p H I S i$ plasmid was mated with the yeast strain AH109 carrying a cDNA library, which was prepared from RNA of 7-week-old rosette leaves of Arabidopsis thaliana and integrated into the $p$ GADT7-Rec vector with the Gal4 activation domain and the leu2 selection marker. The one-hybrid screenings and assays were performed as described in the manufacturer's protocols. Two independent clones partially coding for ERF4 clones were found in the screening. Therefore, the full-length cDNA of ERF4 was cloned into $p$ GADT7-Rec vector and transformed again into Y187 cells carrying the CAT3 driven HIS3 gene to confirm the interaction.

\subsection{Expression and Extraction of Recombinant Proteins for DNA-Protein-Interaction-Enzyme-linked Immunosorbent Assay (DPI-ELISA), Pull-Down Assay and in vitro Protein Degradation Assay}

The coding sequences of the two ERF4 isoforms [27] were cloned into the expression vector pETG-10A with N-terminal hexahistidine-tag (6xHIS-tag) and in the pDEST-15 expression vector with N-terminal Gluthathione-S-Transferase (GST)-tag (for pull-down assay). For protein expression, the E. coli strain BL21 Rosetta was used. The transformed cells were grown in $5 \mathrm{ml}$ selective LB (lysogeny broth) medium overnight and the next day a fresh $50 \mathrm{ml}$ culture was inoculated with $500 \mu \mathrm{L}$ of the overnight culture and grown in selective LB medium until it reached $\mathrm{OD}_{595}$ of 0.5 . Protein expression was induced by adding IPTG (Isopropyl- $\beta$-D-thiogalactopyranoside) to a final concentration of $1 \mathrm{mM}$. After $4 \mathrm{~h}$ of shaking at $30^{\circ} \mathrm{C}$ the cells were harvested by centrifugation $\left(4600 \mathrm{rpm}, 20 \mathrm{~min}, 4^{\circ} \mathrm{C}\right)$. The pellet was resuspended in protein extraction buffer $(500 \mathrm{mM} \mathrm{NaCl}$, $5 \mathrm{mM}$ Imidazole, $20 \mathrm{mM}$ Tris-HCl, $2 \mathrm{mM}$ sodium azide, $\mathrm{pH}$ 7.0, 1 x complete proteinase inhibitor without ethylenediaminetetraacetic acid (Roche, Basel, Switzerland) was added freshly). Proteins were extracted under native conditions by sonicating and the protein concentration was measured in a Bradford assay (Bio-Rad, Munich, Germany).

\subsection{DPI-ELISA}

Streptavidin-coated, transparent 96-well ELISA plates (Thermo Scientific, Waltham, MA, USA) were used to immobilize double-stranded (ds) oligonucleotides (Biomers, Ulm, Germany). The 5'biotinylated forward and its complementary reverse oligonucleotide were annealed at $95^{\circ} \mathrm{C}$ for $5 \mathrm{~min}$, followed by a slow, stepwise cooling down to room temperature. 2 pmol ds oligonucleotides were added per well in a total volume of $60 \mu \mathrm{L}$ and incubated for $1 \mathrm{~h}$. The liquid was removed after each step. After $1 \mathrm{~h}$ of blocking (60 $\mu \mathrm{L}$ Roche blocking solution), 5, 10 and $25 \mu \mathrm{g}$ of protein crude extracts were diluted with protein dilution buffer $(4 \mathrm{mM}$ Hepes pH 7.5, $100 \mathrm{mM} \mathrm{KCl,} \mathrm{8 \%}$ (v/v) glycerol) and the mixture was incubated for $1 \mathrm{~h}$. Two washing steps with $100 \mu \mathrm{L}$ Qiagen wash buffer were performed, $60 \mu \mathrm{L}$ of Penta-His-horseradish peroxidase conjugate antibody (Qiagen, Venlo, The Netherlands) was added (diluted 1:1500 in Qiagen wash buffer) and incubated for $1 \mathrm{~h}$. After another two washing steps, the interaction was visualized using the substrate of the peroxidase, o-phenylenediamine dihydrochloride (OPD tablets, Thermo Scientific). This resulted in a yellow product, which was detected in a plate reader (TECAN Safire SFluor4) at $492 \mathrm{~nm}$. 


\subsection{Pull-Down Assay}

GST-ERF4-A (49.6 kDa), GST-ERF4-R (51.7 kDa), 6xHIS-ERF4-A (24.5 kDa) and 6xHIS-ERF4-R $(26.6 \mathrm{kDa})$ fusion proteins were expressed as previously described. $500 \mu \mathrm{g}$ total protein of the crude extracts were incubated at room temperature for $1 \mathrm{~h}$ with continuous shaking. HIS-select nickel magnetic agarose beads (Sigma-Aldrich, St. Louis, MO, USA) were used according to manufacturer's instructions to pull on the 6xHIS-tagged fusion proteins (wash buffer: $50 \mathrm{mM} \mathrm{NaH}_{2} \mathrm{PO}_{4}, 300 \mathrm{mM} \mathrm{NaCl}$, $10 \mathrm{mM}$ imidazole, elution buffer: $50 \mathrm{mM}$ sodium phosphate $\mathrm{pH}$ 8,0, 0,3 M NaCl, $300 \mathrm{mM}$ imidazole). The eluted fraction was analyzed by SDS-PAGE using a monoclonal anti-Glutathione-S-Transferase (GST) antibody (Sigma-Aldrich) and semi-dry Western Blot.

\subsection{In Vitro Protein Degradation Assay}

Leaf 7-8 and 9-13 of 49-day-old Arabidopsis Col-0 plants were harvested separately. Recombinant 6xHIS-ERF4-A and 6xHIS-ERF4-R fusion proteins were produced in bacteria as described earlier. The protein isolation buffer was exchanged by using Amicon Ultra-4 Centrifugal Filter Devices (Merck Millipore, Burlington, MA, USA) with a solution containing $20 \mathrm{mM}$ Tris (pH 8.0) and $100 \mathrm{mM} \mathrm{NaCl}$. The cell-free in vitro degradation assay was modified from Reference [35]. The leaf material was ground in liquid nitrogen and the powder was suspended in a buffer containing $50 \mathrm{mM}$ Tris (pH 7.5), $10 \mathrm{mM} \mathrm{NaCl}, 10 \mathrm{mM} \mathrm{MgCl} 2,5 \mathrm{mM}$ dithiothreitol and $2 \mathrm{mM}$ ATP. After centrifugation (14,000 rpm, $\left.10 \mathrm{~min}, 4^{\circ} \mathrm{C}\right) 25 \mu \mathrm{g}$ total protein of the bacterial crude lysate were added into the plant extracts and incubated at room temperature for 0, 15, 30, 60 and $120 \mathrm{~min}$. Subsequently, SDS loading buffer was added and the samples were boiled at $95^{\circ} \mathrm{C}$ to terminate the reaction and to denature the proteins. The proteins were detected by SDS-PAGE and immunoblot analysis with a penta-HIS-HRP conjugate antibody (Qiagen). E. coli extracts were used as negative control.

\subsection{Protoplast Leaf Transfection}

The transient GUS (B-glucuronidase) reporter gene assays and BiFC were performed in protoplasts, which were derived from cell suspension culture cells of Arabidopsis thaliana Col-0 and in leaf protoplasts of Col-0, erf4 and esp/esr knock-out mutants. They were transfected with plasmid DNA purified with the Gene JET Plasmid Midiprep kit (Thermo Scientific) for GUS Assays or the Nucleo-Bond Xtra Midi kit (Macherey-Nagel, Düren, Germany) for BiFC. Protoplasts were transiently transformed with different concentrations of the respective plasmid DNA following the protocol published in Reference [36]. For details, see the protocol on http:/ / www.zmbp.uni-tuebingen.de/cfacilit/plant-transformation.html.

\subsection{GUS Reporter-Gene Assay in Protoplasts}

For the GUS assays, $1.8 \mathrm{kbp}$ upstream of the start codon of CAT3 and $2.8 \mathrm{kbp}$ upstream of the start codon of WRKY53 were cloned into the GUS reporter plasmid pBGWFS7.0, respectively. The coding sequences of ERF4-A and ERF4-R [27] were cloned in the binary plant transformation vector pJAN33. Arabidopsis protoplasts were transformed as previously described with $3 \mu \mathrm{g}$ effector constructs, $2.5 \mu \mathrm{g}$ reporter plasmid and $0.1 \mu \mathrm{g}$ of a 35S:Luciferase plasmid (pBT8-35SLUCm3) for normalization purposes. The protoplasts were incubated over night at room temperature and the GUS assay was performed the next morning as described by Jefferson et al. [37].

\subsection{BiFC and Flow Cytometry}

For the BiFC assay, the coding sequence of ERF4-R and ERF4- $A$ as well as WRKY53 (as a negative control with ERF4 isoforms and as positive control with itself) were cloned into the BiFC-2in1-NN vector [38]. It fuses the $\mathrm{N}$ - and C-terminal part of eYFP to the $\mathrm{N}$-termini of both interaction partners and it contains RFP (red fluorescent protein) as a transformation control. Protoplasts were transfected with $3 \mu \mathrm{g}$ of the plasmid, covering the 8 possible combinations between the potential interaction 
partners and the negative control. After incubation overnight, fluorescence was quantified by flow cytometry using a CytoFLEX (Beckman Coulter, Brea, CA, USA). Both the internal mRFP and any reconstituted eYFP were excited by the on board $488 \mathrm{~nm}$ laser. For eYFP, peak emission was captured in FL1 (525/40 nm) and for RFP in FL3 (610/20 nm). After compensation, the percentage of cells with eYFP signal was determined. The results were means from 7 experiments for the ERF4 homo- and heterodimers and 3 experiments for the combinations with WRKY53. Furthermore, the interactions were visualized with a Leica TCS SP8 microscope. eYFP was excited at $514 \mathrm{~nm}$ and the emission was recorded at 519-560 nm, whereas mRFP was excited at $561 \mathrm{~nm}$ and the emission was recorded at $566-637 \mathrm{~nm}$.

\subsection{Plant Material}

Arabidopsis thaliana plants were grown in standard soil under long-day conditions ( $16 \mathrm{~h}$ day, $8 \mathrm{~h}$ night) at an ambient temperature of $20^{\circ} \mathrm{C}$ with a moderate light intensity $\left(80-100 \mu \mathrm{E} / \mathrm{m}^{2} / \mathrm{s}\right)$. Individual leaves were labelled with differently colored threads according to their age. This allowed the identification of the leaf numbers within the first rosette even in very late stages of senescence [39]. Plants were always harvested at the same time in the morning in order to avoid circadian effects. The T-DNA insertion lines of ERF4 (SALK_073394), FPA (SAIL720_B10, SALK_011615, SAIL_849_F10) and ESP/ESR (SALK_055029C) were obtained from the Nottingham Arabidopsis Stock Centre (NASC). Homozygous plants were verified by PCR using combinations of gene specific primers and the T-DNA left border primer (Lba1). Plants overexpressing the different isoforms of ERF4, as well as complementation lines were kindly provided by G. Simpson and K. Shirasu [27]. Different plant lines overexpressing ERF4-R isoform were obtained from and published by T. Koyama [17].

\subsection{Semi-quantitative-PCR (sqRT-PCR) and qRT-PCR}

Total RNA was extracted with the RNeasy plant mini kit (Qiagen) and the subsequent cDNA synthesis was done with RevertAid reverse transcriptase (Thermo Scientific) and oligo (dT) primer using $200 \mu \mathrm{g}$ of RNA. qRT-PCR was performed using Kapa SYBR®Fast Bio-rad iCycler (Kapa Biosystems, Wilmington, MA, USA) master mix following the manufacturer's instructions in a final volume of $8 \mu \mathrm{L}$ including $3.5 \mu \mathrm{L}$ of 1:5 diluted cDNA. The expression of the genes analyzed was normalized to ACTIN2 (ACT2) according to the method published by Pfaffl [40]. sqRT-PCR products were amplified in $10 \mu \mathrm{L}$ PCR reactions containing $1 \mu \mathrm{L}$ of cDNA for amplification of ACT2, $2 \mu \mathrm{L}$ for ERF4-R and $3 \mu \mathrm{L}$ for ERF4- $A$. Red Mastermix (2x) (Genaxxon bioscience, Ulm, Germany) was used with $0.5 \mu \mathrm{M}$ primer P1, P2 or P3 (see Table S1). The exponential range of amplification was determined for each set of primers and accordingly different numbers of cycles were used ( 26 for $A C T 2,27$ for ERF4- $R$ and 36 for ERF4- $A$ ) with different annealing temperatures $\left(55^{\circ} \mathrm{C}\right.$ for $A C T 2,62{ }^{\circ} \mathrm{C}$ for ERF4-R and $64^{\circ} \mathrm{C}$ for ERF4-R; Figure S3A). PCR products were separated on a $1 \%$ agarose gel with subsequent ethidium bromide staining and band intensity was analyzed using ImageJ.

\subsection{Senescence Phenotyping}

To assess differences in the progression of senescence between the plant lines, we measured a variety of parameters, which indicate the state of senescence from 25 up to 70 days after sowing (DAS). All methods are described in detail by Bresson et al. [39]. Electrolyte leakage was measured using a conductivity meter (CM100-2, Reid and Associates). In order to measure the hydrogen peroxide $\left(\mathrm{H}_{2} \mathrm{O}_{2}\right)$ level, 3,3'-diaminobenzidine (DAB) staining or the fluorescent dye H2DCFDA were used. The activity of photosystem II (PSII) was assessed by Fv/Fm values (using the Imaging- PAM chlorophyll fluorometer Maxi version; ver. 2-46i, Walz $\mathrm{GmbH}$, Effeltrich, Germany) and the status of chlorophyll breakdown was measured by extraction of chlorophyll (Chl). Leaf No. 6 was used for native catalase zymograms, RNA was extracted from leaves No. 7 and 8 and the leaf color was assessed with the automated colorimetric assay (ACA) published in Bresson et al. [39]. Chl content in the ERF4 complementation lines was measured with an atLEAF+Chl meter in leaf No. 5, three times 
per leaf and the values were averaged. All phenotyping experiments were done with a minimum of four biological replicates and experiments were performed at least three times independently.

\subsection{Catalase Zymograms and Immunodetection}

Plant protein was extracted out of frozen leaves by grinding material in $200 \mu \mathrm{L}$ extraction buffer (100 mM Tris, 20\% glycerol (v/v), $30 \mathrm{mM} \mathrm{DTT,} \mathrm{pH}$ 8). The samples were centrifuged for $15 \mathrm{~min}$ at $14,000 \mathrm{rpm}$ and $4{ }^{\circ} \mathrm{C}$. Total protein concentration of the supernatant was measured via Bradford assay (Bio-Rad) and $10 \mu \mathrm{g}$ total protein was loaded on native polyacrylamide (PAA) gels (6\% PAA, $1 \mathrm{M}$ Tris, pH 6.8; running buffer: $25 \mathrm{mM}$ Tris, $250 \mathrm{mM}$ Glycine, $\mathrm{pH}$ 8.3). After protein separation, the gels were rinsed twice with water, incubated for $2 \mathrm{~min}$ in a $0.01 \% \mathrm{H}_{2} \mathrm{O}_{2}$ solution and rinsed again twice with water. The staining was performed in a solution containing $1 \% \mathrm{FeCl}_{3}$ and $1 \% \mathrm{~K}_{3}\left(\mathrm{Fe}(\mathrm{CN})_{6}\right)(\mathrm{w} / \mathrm{v})$ until catalase activity bands became visible $(\sim 3 \mathrm{~min})$. The reaction was stopped by rinsing gels with water. For immunodetection the native PAA gel was blotted on a nitrocellulose membrane. After blotting, the membrane was washed twice with Tris-buffered saline (TBS) and blocked with $3 \%$ milk powder in TBS-Tween 20 (TBS-T). Polyclonal anti-rye-CAT antibodies in 1.5\% milk powder were used, followed by secondary peroxidase-conjugated antibodies for visualization.

\section{Results}

\subsection{Impact of ERF-A and ERF-R on Senescence}

ERF4 is a transcription factor, which can undergo alternative polyadenylation resulting in the co-existence of two different isoforms, ERF-A and ERF-R [27]. We were interested to find out when both forms are produced during plant development and whether or not they have an impact on senescence. Therefore, we used an erf4 mutant line, an ERF4- $A$ and different ERF4-R overexpressing lines all in Col-0 background. The plants were grown side by side with Col-0 wildtype plants to compare senescence onset and progression. These phenotyping experiments were repeated three times with similar results. In order to investigate leaf senescence of the different plant lines, optical appearance was scored for several parameters during leaf development at the same rosette position from 25 to 70 days after sowing (DAS). Therefore, the true leaves (without the cotyledons) were labelled with different threads following a color code. Leaves of one rosette were sorted according to their age and corresponding leaves of the different lines were compared (Figure 1A). A statistical analysis of at least five plants was used to capture variability between individual plants of the same lines. A colorimetric analysis consisted in categorizing leaves into four groups depending on their leaf color: fully green, green/yellow, fully yellow, brown/dry (Figure 1B). Compared to Col-0 the 35S:ERF4- $R$ line showed more signs of senescence, whereas the erf4 line was less senescent at the same time point according to visual features (Figure 1A,B) indicating that the 35S:ERF4- $R$ plants were accelerated and the erf4 plants delayed in senescence. The 35S:ERF4- $A$ plants behaved intermediately; at 41 DAS they were slightly accelerated whereas from 46 DAS onward, they appeared to be more and more delayed. The photosynthetic capacity was analyzed by chlorophyll fluorescence measurements of leaf No. 5 (Figure 1C). Consistent with the colorimetric analysis, the activity of photosystem II declined earlier in 35S:ERF4-R leaves compared to Col-0 leaves, whereas this became more obvious in erf4 mutant or ERF4- $A$ overexpressing leaves much later. Membrane integrity was monitored by measuring electrolyte leakage (EL) of leaf No. 3 (Figure 1D). 35S:ERF4-R line displayed higher membrane deterioration at 37 DAS compared to Col-0. In very late stages (53 DAS), Col-0 and 35S:ERF4-R plants did not show any more differences, whereas erf4 and 35S:ERF4- $A$ had higher membrane integrity compared to wild type. Intracellular ROS production was measured in leaf No. 9 by $\mathrm{H}_{2}$ DCF-DA fluorescence (Figure 1E) and diaminobenzidine (DAB)-staining (Figure 1F). A significantly lower increase of intracellular $\mathrm{H}_{2} \mathrm{O}_{2}$ was detected in erf4 mutant plants with advancing senescence compared to wildtype plants. Again, the 35S:ERF4- $A$ overexpressing plants were more similar to the mutant line, whereas the 35S:ERF4- $R$ 
line showed a faster increase in $\mathrm{H}_{2} \mathrm{O}_{2}$ content supporting the results of the colorimetric analysis (Figure 1A).

A
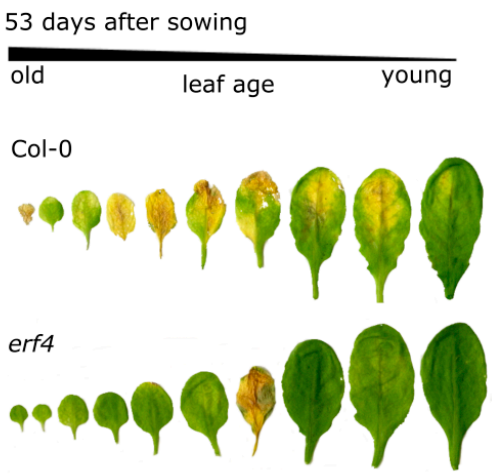

35S:ERF4-R $\operatorname{sen} 9949$

35S:ERF4-A

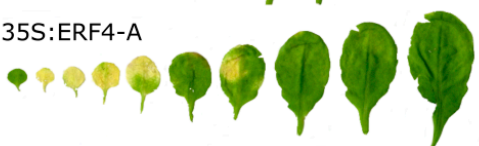

B
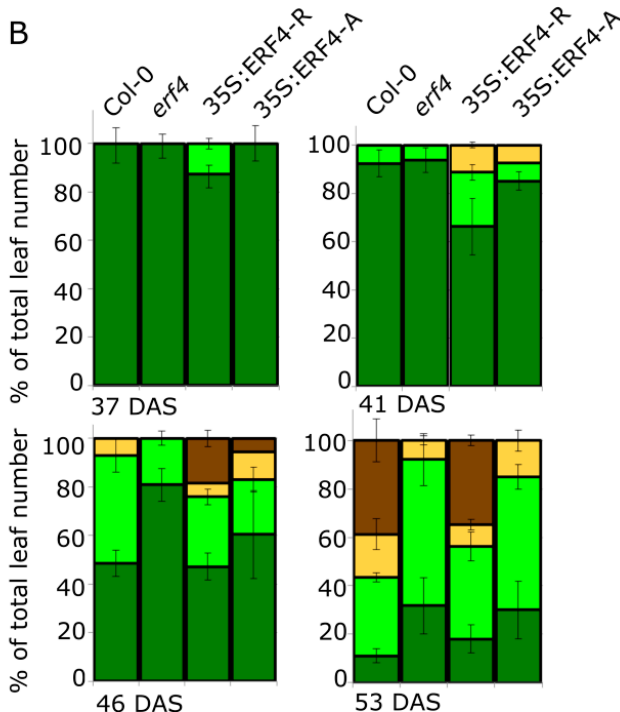

color

$\square$ brown $\square$ yellow $\square$ green-yellow $\square$ green
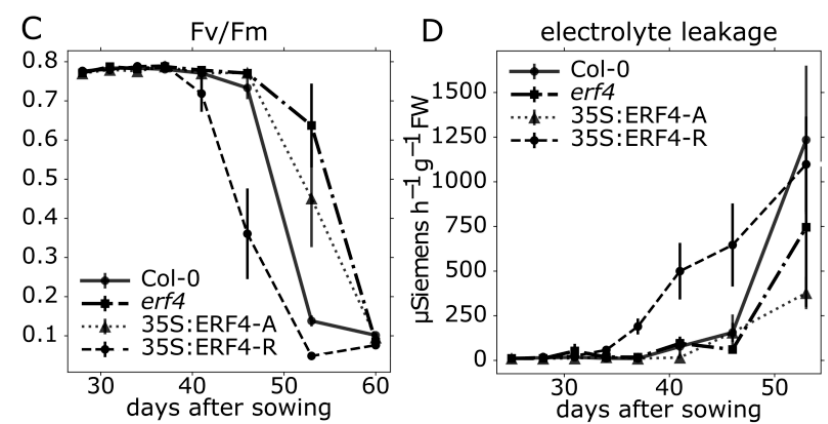

$\mathrm{F}$ plant age
[days after sowing] 35S:ERF4-R Col-0

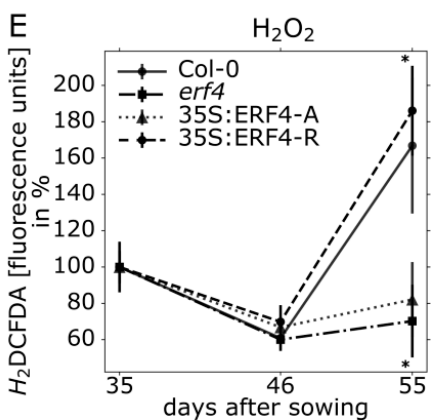

$\begin{array}{llll}38 & 47 \quad 53 \quad 62\end{array}$

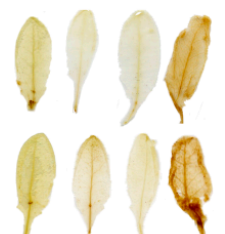

Figure 1. Senescence parameters analyzed in plant lines with altered ERF4 expression. Col-0, 35S:ERF4-R, 35S:ERF4- $A$ and erf4 mutant plants were analyzed over development. (A) Representative pictures for rosette leaves No. 1-10, which were sorted according to their age 53 days after sowing (DAS). (B) Rosette leaves were categorized in four groups according to their color (fully green, green/yellow, fully yellow, brown/dry) and percentage of each category is depicted. (C) Fv/Fm values in leaf No. 5 were measured with the pulse amplitude modulation (PAM) method. (D) Electrolyte leakage (EL) over time was measured in single detached leaves No. 4 using a conductivity meter. Values are normalized to leaf fresh weight. (E) Intracellular $\mathrm{H}_{2} \mathrm{O}_{2}$ content per leaf was measured in leaf No. 9 using the fluorescent dye $\mathrm{H}_{2}$ DCFDA. Values are normalized to leaf weight. Data represent means of 5 (A-D) or 10 (E) biological replicates, error bars present \pm SE. (F) $\mathrm{H}_{2} \mathrm{O}_{2}$ content in leaf No. 9 is visualized by DAB (3,3-diaminobenzidine)-staining. One representative example is shown. Experiments were repeated three times with similar results. 
For comparison of the different lines at the same time point, it is important that their general development is not significantly altered. None of the lines showed a severe impairment in development (Figure S1A-G). The ERF4-R overexpression lines showed a slightly delayed flowering and silique emergence (Figure S1E,F) and had more smaller, less dense leaves (Figure S1C,D,G) whereas erf4 plants had a bigger leaf area and were heavier compared to wildtype plants (Figure S1D). These minor changes in overall development still allow comparison of the lines.

Gene expression of senescence-associated genes (SAGs) was analyzed by quantitative real-time PCR using leaf No. 7 (Figure S2). The lower transcript levels of the senescence-upregulated short chain alcohol dehydrogenase SAG13 (At2g29350) suggest that the erf4 and the 35S:ERF4- $A$ line are both delayed in senescence-associated gene expression compared to Col-0. The ERF4-R overexpression line showed a faster increase of $S A G 13$ mRNA levels until 46 DAS, then transcript levels in Col-0 reached higher values pointing to a slightly accelerated senescence compared to Col-0. SAG12 (At5g45890), a senescence-upregulated cysteine protease that is often used as marker gene in late senescence, showed a different pattern for the later stages of leaf senescence. Col- 0 and the mutant line showed the highest expression level, whereas the overexpression of ERF4- $A$ resulted in the lowest expression of SAG12 at 53 DAS. Down-regulation of RUBISCO (RBCS1) was not much altered in all lines indicating that ERF4 affects only part of the senescence reprogramming at different time points of senescence.

Taken together, the results of the phenotyping experiments reveal that the erf4 plants show delayed senescence, 35S:ERF4- $A$ plants are only slightly delayed in senescence and more similar to Col-0, 35S:ERF4- $R$ plants show an accelerated senescence phenotype, more pronounced in earlier stages and then becoming progressively indistinguishable to Col-0 plants in later senescence stages.

\subsection{ERF4-A mRNA is Less Abundant than ERF4-R, but the Protein is Less Prone to Degradation In Vitro}

In order to get an idea about the abundance of the ERF4 isoforms at different stages of leaf senescence, we analyzed the relative amount of the mRNA forms in Arabidopsis Col-0 plants from 31 to 46 DAS by conventional RT-PCR as described by Lyons et al. [27]. Three different mRNA molecules can be derived from ERF4 transcription: ERF4-R, ERF4-IR and ERF4-A as illustrated in Figure 2A. $E R F 4-R$ is created by using the first polyadenylation site, ERF4-IR by using the second polyadenylation site without splicing of an intron, which now exists in the longer mRNA. Therefore, this form is called IR for intron retention. ERF4- $A$ is also created by using the second polyadenylation site, however, in this form the intron is spliced out, which now leads to the loss of the repressing EAR domain. Therefore, this form is called A for activator. These three mRNA forms lead to two different protein variants whereby ERF4- $A$ mRNA encodes the ERF4-A protein and ERF4-R and ERF4-IR mRNAs both lead to the ERF4-R protein. The nucleotide sequence of ERF4-IR entirely includes the sequence of $E R F 4-R$ and as well as of ERF4- $A$. This is the reason why no sequence specific primers can be designed to distinguish all three forms by quantitative RT-PCR. Therefore, a semi-quantitative RT-PCR approach was chosen using two different primer pairs: $\mathrm{P} 1$ and $\mathrm{P} 3$ differentiate the ERF4-IR form from the ERF4- $A$ form by size and P1 and P2 amplify the ERF4-R+IR. For simplicity, we called the sum of $E R F 4 R+I R$ only $E R F 4-R$ in the following as they encode the same protein. First, we determined the exponential range of amplification (Figure S3A). Thereafter, we used 36 cycles and $3 \mu \mathrm{L}$ cDNA for the ERF4- $A$ and ERF4-IR amplification, 27 cycles and $2 \mu \mathrm{L}$ cDNA for ERF4-R and 27 cycles and $1 \mu \mathrm{L}$ of cDNA for ACTIN2 as reference gene. These initial results indicated that the A-Form is much less abundant than the R-Form. The ERF4-IR mRNAs were even less abundant than the ERF4- $A$ form and, since they code for the same protein as ERF4-R, were not analyzed separately. From these analyses, we determined that the ERF4- $A$ and ERF4-R isoforms show an age-dependent expression, with a higher mRNA abundance in later stages of leaf senescence (Figure 2B). However, after bolting at 31 DAS, a decrease in the expression of ERF4- $A$ can be observed, followed by a constant increase, indicating that both isoforms are not always produced at the same ratio over development (Figure 2C). Moreover, the expression of the different isoforms was also analyzed in the 35S:ERF4-R and 35S:ERF4- $A$ as well as in the erf4 mutant line. (Figure S3B). Both isoforms were clearly overexpressed and overexpression 
of the ERF4-R led to a slight decrease of ERF4- $A$ formation and vice versa. However, how this feedback loop on splicing and polyadenylation is achieved, has to be further investigated.

A ERF4 pre mRNA

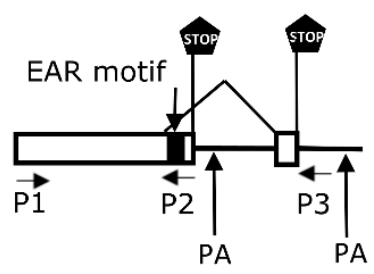

B

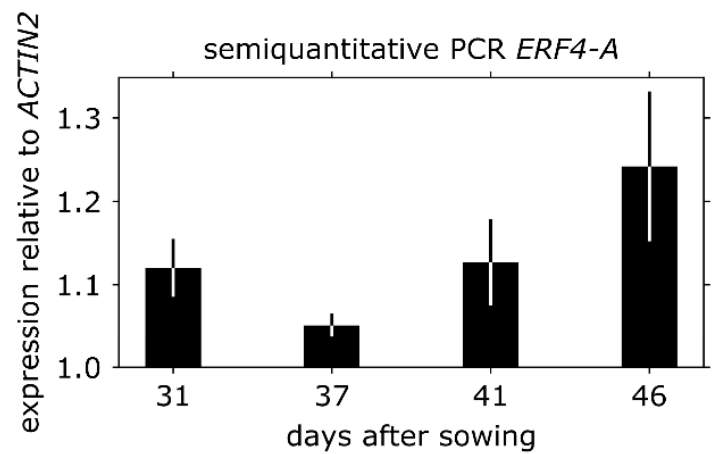

C

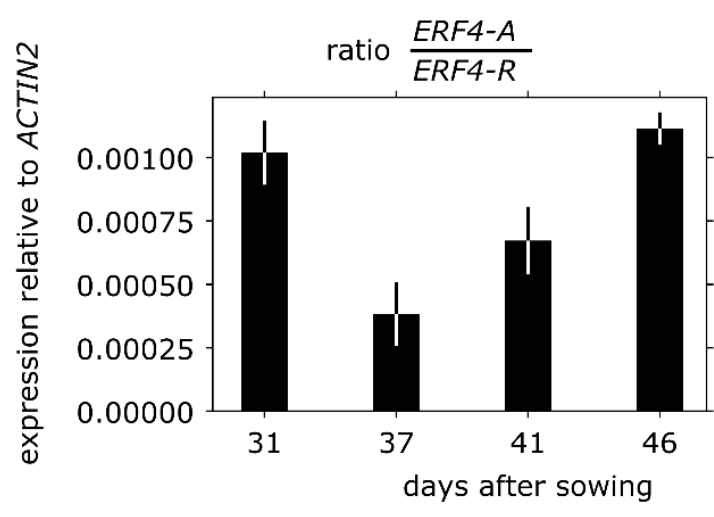

ERF4 isoforms
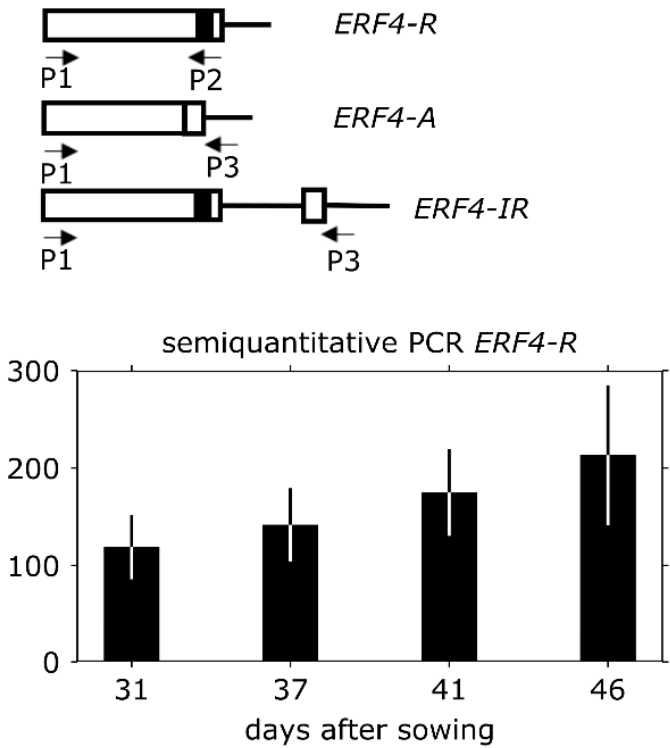

D Leaves 9-13

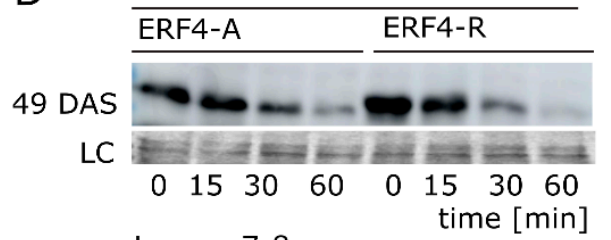

Leaves 7-8 time [min]

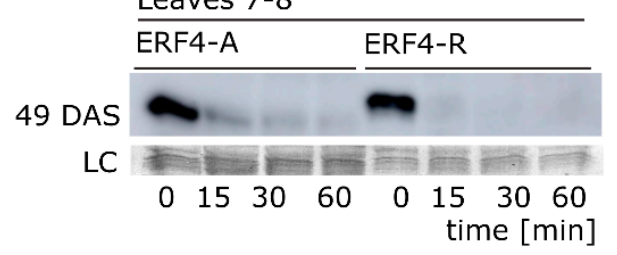

Figure 2. ERF4 isoform expression and protein stability. (A) Schematic illustration of ERF4 pre-mRNA with two different polyadenylation sites and primer binding sites for primer 1 (P1), primer 2 (P2) and primer 3 (P3), which were used for semi-quantitative reverse transcriptase PCR (sqRT-PCR) as described in [27]. Boxes denote exons, lines denote introns and untranslated regions, PA indicates alternative polyadenylation sites, black box indicates the repressing ERF-associated amphiphilic repression (EAR) motif. cDNA of the ERF4 isoforms is shown on the right side. (B) Results of the sqRT-PCR using RNA isolated from Col-0 plants at different developmental stages indicated in days after sowing (DAS). Graph shows expression of ERF4- $A$ ( 36 cycles, $3 \mu \mathrm{L}$ cDNA) and ERF4-R ( 27 cycles, $2 \mu \mathrm{L}$ cDNA), which was quantified using ImageJ and is presented relative to expression of ACTIN2. Error bars indicate $\pm \mathrm{SE}, n=3$. (C) Ratio of ERF4- $A$ to ERF4-R mRNA at different developmental stages (D) Cell-free protein degradation assay. 6xHIS-tagged ERF4-R (26.6 kDa) and ERF4-A (24.5 kDa) proteins were incubated in protein extract of young (No. 9-13) and middle old leaves (No. 7 and 8) for 0-60 min. Five plants were pooled for protein extraction and were harvested 49 days after sowing (DAS). Amido black staining of the upper part of the polyvinylidene difluoride (PVDF) membrane is shown as loading control (LC).

To investigate whether the lower abundance of ERF4-A is counterbalanced by a higher protein stability, we subjected recombinant proteins of both isoforms to in vitro proteolysis by plant extracts. Therefore, epitope-tagged versions of the proteins were expressed in E. coli and $25 \mu \mathrm{g}$ of the protein 
crude lysates containing the recombinant proteins were incubated for $0,15,30$ and 60 min with Arabidopsis leaf extracts, which were derived from selected rosette leaves (9-13 or 7-8) at 49 DAS. The ERF protein amount, which remained after incubation, was assessed by immunodetection. Both ERF4 isoforms were rapidly degraded by the plant extracts (Figure 2D), whereas ERF4 protein amounts were not reduced under the same conditions by bacterial cell lysates (Figure S3C), suggesting that ERF4 isoforms are degraded by plant-specific proteins and/or the plants' proteasome. Both isoforms were more stable in extracts of younger leaves (No. 9-13) than in extracts of older leaves (No. 7-8); ERF4-A was in general more stable than ERF4-R. This suggests that both ERF4 isoforms are present throughout the whole process of leaf senescence, lower expression in younger leaves is counterbalanced by higher protein stability in this tissue, and, in addition, lower ERF4- $A$ mRNA amounts are compensated by a higher protein stability of ERF4-A compared to ERF4-R.

\subsection{Senescence Analyses of erf4 Complementation Lines}

To further analyze the impact of each isoform on senescence, we characterized complementation lines, which express the ERF4-R or ERF4- $A$ coding sequence under the control of the native ERF4 promoter in the erf4 background (cERF4-R and cERF4-A). These lines were obtained from Lyons et al. [27]. After verification of the isoforms' expression by semi-quantitative PCR (Figure S4), the plants were grown along with Col-0 and the erf4 plants under long-day conditions and low light intensities $\left(30 \mu \mathrm{E} / \mathrm{m}^{2} / \mathrm{s}\right)$ to slow down development and increase the resolution of senescence. As before, leaves were sorted according to their age and one example (55 DAS) is presented in Figure 3B. As the plants were grown under low light conditions, Col-0 leaves were less senescent at 55 DAS compared to Figure 1A,B at 53 DAS. The differences between the complementation lines were very subtle. In order to quantify leaf color more precisely than by eye, we used an automated colorimetric assay (ACA) to classify the color values pixel-wise (Figure 3A, [39]). According to the ACA, both lines were able to complement the mutation of ERF4 almost completely with a tendency of cERF4-A to complement slightly better (Figure 3A,B).

DAB-staining indicated that $\mathrm{H}_{2} \mathrm{O}_{2}$ levels in erf4 plants are lower compared to Col-0 levels as the plants age. Both, ERF4- $A$ and ERF4-R, complemented the erf4 mutant, with ERF- $A$ again slighly more effective than the $E R F-R$ form, as staining of cERF4-A leaves appear to be more similar to wildtype than to cERF4-R leaves (Figure 3C). Fv / Fm levels of cERF4-A resembled those of wildtype plants and decreased earlier than cERF4-R and the mutant line; however, from 55 DAS onwards both complementation lines complemented equally well (Figure 3D). With regard to EL in leaf No. 4, the cERF4-A line also shows the tendency of complementing ERF4 loss slightly better than cERF4-R (Figure 3E). In summary, both isoforms can complement the loss of ERF4 in erf4 plants almost to wildtype level with a tendency of the ERF4- $A$ for a slightly better complementation. This is very surprising as Lyons et al. [27] have already shown that both forms can act antagonistically on gene expression, at least on PDF1.2. 
A

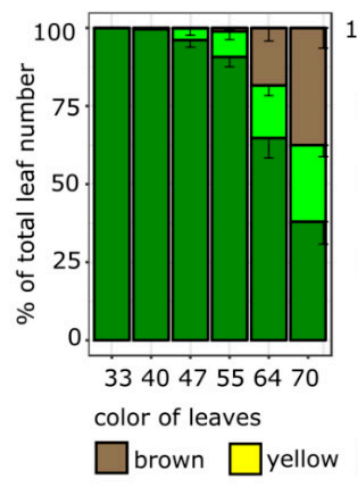

B

55 days after sowing

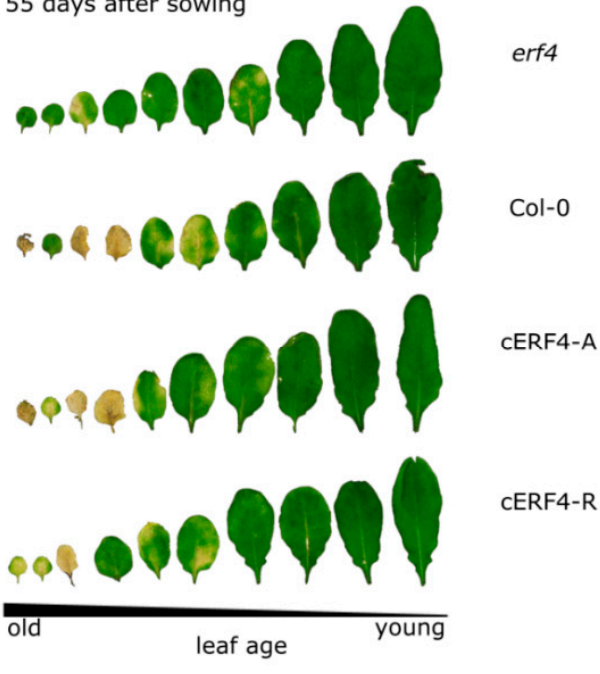

D

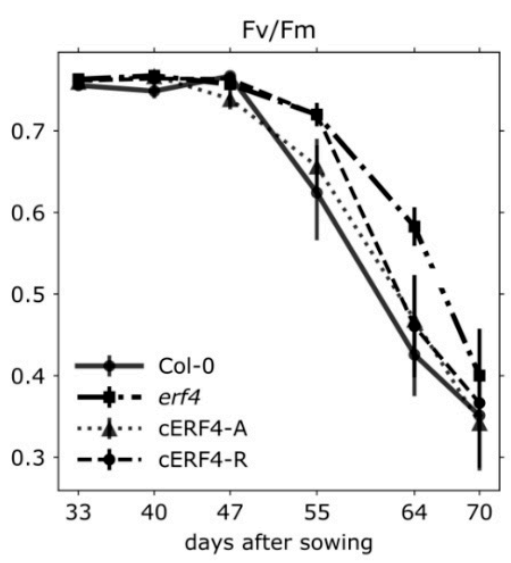

Col-0

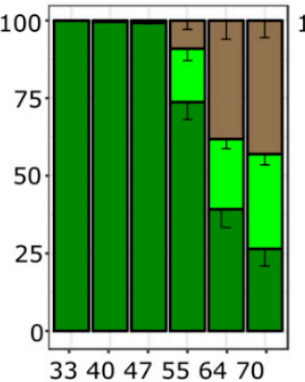

green-yellow $\square$ green

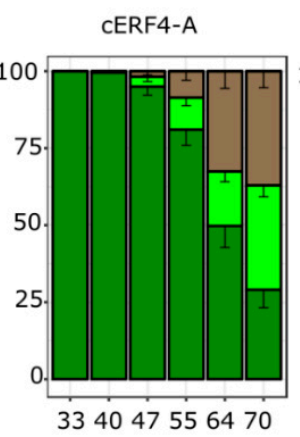

$$
\text { reen }
$$

c
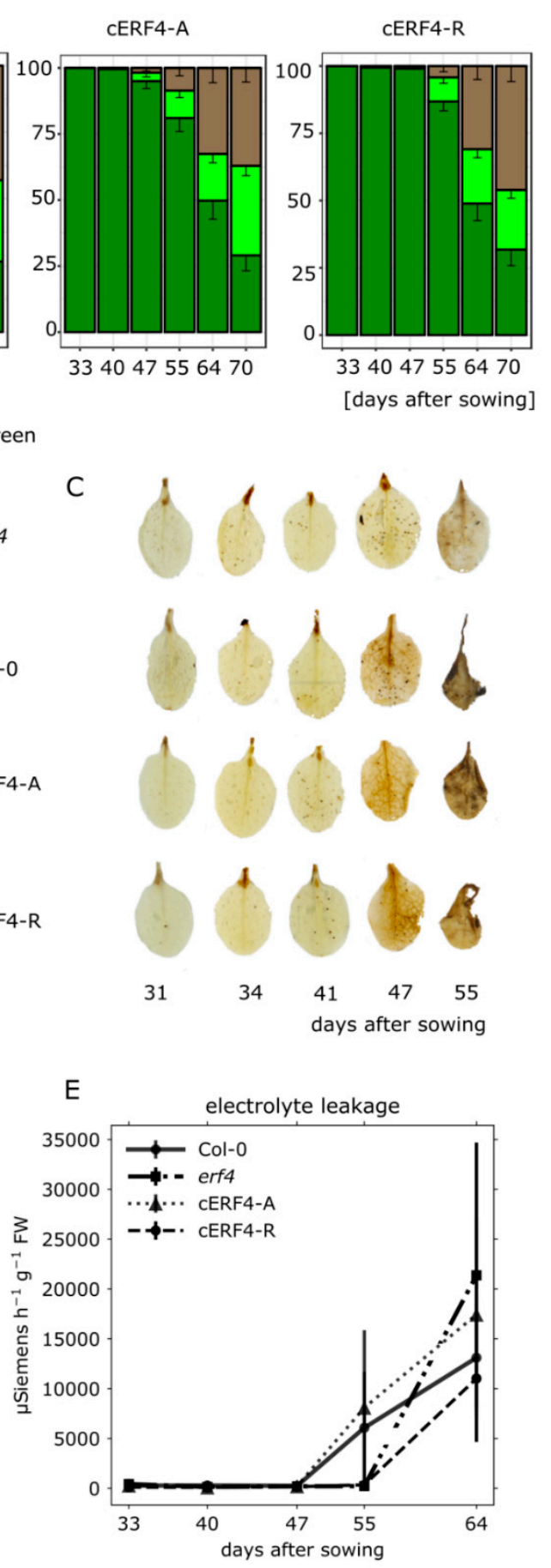

Figure 3. Complementation of ERF4 loss of function by ERF4-A or ERF4-R. Senescence phenotype and parameters were analyzed in Col-0, erf4 mutants, and erf4 mutant plants complemented with either ERF4-promoter:ERF4-A (cERF4-A) or ERF4-promoter:ERF4-R constructs (cERF4-R). (A) Automated colorimetric assay, in which rosette leaves are categorized according to color in four groups (green, green-yellow, yellow, brown). (B) Representative pictures of rosette leaves No. 1-10, which were sorted according to leaf age 55 DAS. (C) One representative picture of five biological replicates for DAB-staining in leaf No. 4 at 31-55 DAS. These plants have been raised under normal light intensities $(80 \mu \mathrm{E} / \mathrm{m} 2 / \mathrm{s})$. (D) $\mathrm{Fv} / \mathrm{Fm}$ values in rosette leaves were measured with pulse amplitude modulation (PAM). (E) Electrolyte Leakage (EL) was measured with a conductivity meter in detached leaves No. 4 of another experimental series. Values are normalized to fresh weight. Data A, D and E represent means of at least four biological replicates, error bars indicate $\pm \mathrm{SE}$. 


\subsection{Impact of ERF4 on the Senescence Regulator WRKY53}

As shown by Koyama and coworkers [17], WRKY genes are significantly upregulated in ERF4-R overexpressing lines and WRKY53 senescence-associated induction is eliminated in the erf4/erf8 double mutant. The authors explained the effect by the action of ESP/ESR, which is a negative regulator of WRKY53 expression and activity [18]. By ChIP, ESP/ESR was shown to be a direct target of ERF4 acting as repressor on ESP/ESR expression [17]. In order to investigate whether there is also a direct effect of both ERF4 isoforms on the expression of WRKY53, we transiently co-transformed a $2.8 \mathrm{kbp}$ WRKY53-promoter:GUS construct with 35S:ERF4-R and 35S:ERF4- $A$ effector constructs in Arabidopsis Col-0 or esp/esr protoplasts. In the presence of ESP/ESR, WRKY53 expression was increased approx. 5-fold by ERF4-R overexpression (Figure 4), which is in the same range as in the microarray experiment of Koyama et al. [17]. However, in the absence of ESP/ESR in esp/esr protoplasts, WRKY53 expression was induced approx. 2-fold by ERF4-R overexpression, indicating that WRKY53 expression is also influenced in an ESP/ESR-independent pathway (Figure 4). Overexpression of ERF4-A showed a weak but positive effect (approx. 1.5-fold) on this promoter, which was almost completely missing in the esr/esp protoplasts (Figure 4) indicating that ERF4-A has only a weak effect but uses exclusively the ESP/ESR pathway.

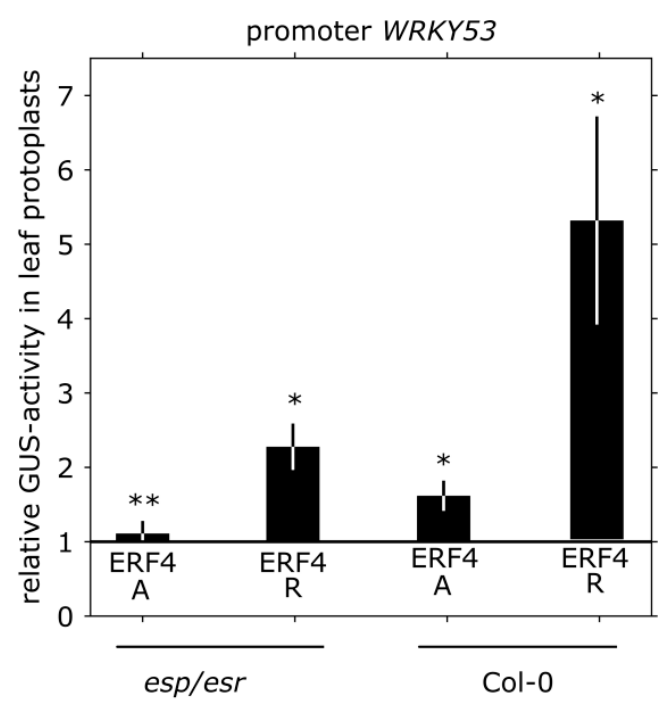

Figure 4. Impact of ERF4 on WRKY53 expression. Transient expression assays were performed in Arabidopsis protoplasts with a $2.8 \mathrm{kbp}$ fragment of the WKRY53 promoter that drives expression of GUS in Col-0 and esp/esr mutant leaf protoplasts. Values represent fold-change of GUS-activity relative to the empty vector after normalization to luciferase activity from a minimum of four experiments. Error bars indicate \pm SE. Statistical differences were determined by one sample t-test $\left({ }^{*} p \leq 0.05,{ }^{* *} p \leq 0.005\right.$, *** $p \leq 0.0005)$.

\subsection{Isolation and Characterization of CATALASE3 (CAT3) as Direct Target Gene of ERF4}

In a yeast-one-hybid $(\mathrm{Y} 1 \mathrm{H})$ screen, which was performed to find potential regulatory proteins that interact with the CAT3 promoter, different CAT3 promoter fragments were cloned in front of reporter genes (His and Ade, LacZ) and brought into yeast cells together with a cDNA library obtained from 7-week-old Arabidopsis leaves. cDNA insertions were sequenced and identified from yeast cells growing on selection media. Among others, partial sequences of ERF4 were identified in two independent clones to bind to a 150-bp fragment (-332 to -182) of the CAT3 promoter (Figure 5A). Therefore, the full-length coding sequence of $E R F 4-R$, which is the predominantly expressed isoform, was cloned into the pGADT7 vector and transformed into the reporter yeast strain Y187 [pHISi-CAT3] and growth on selection media could be confirmed. Therefore, the full-length ERF4-R protein binds to a cis-element in the CAT3 promoter. The DNA-binding of ERF4 to the CAT3 promoter was further 
analyzed in vitro by DPI-ELISA. For DPI-ELISA, the coding sequence of both ERF4- $R$ and ERF4- $A$ isoforms were cloned in pETG10A with N-terminal hexa-histidine-tag (6xHIS-tag) and expressed in bacteria. A 55-bp biotinylated DNA fragment of the CAT3 promoter sequence, which was identified in the yeast-one-hybrid screen and contains the DRE motif CAGCC, an already known binding motif for ERF4 [41], was used (Figure 5A). Whereas the crude lysate of the Escherichia coli (E. coli) strain expressing the empty vector did not show any binding activity, both ERF4 isoforms were able to bind to this fragment (Figure 5B).

A ERF4 binding region found in Y1H

$-332-182$

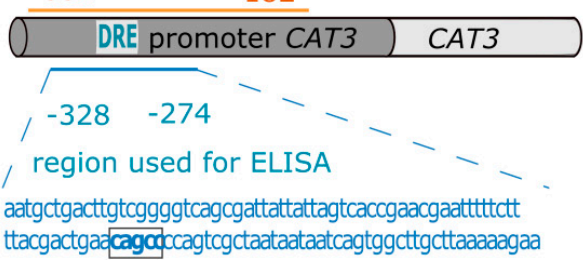

DRE-motif

B

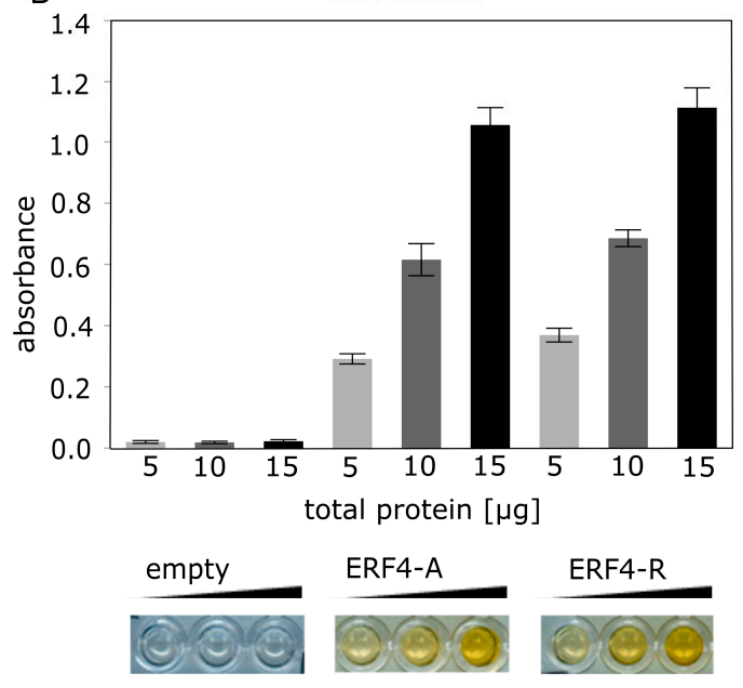

C

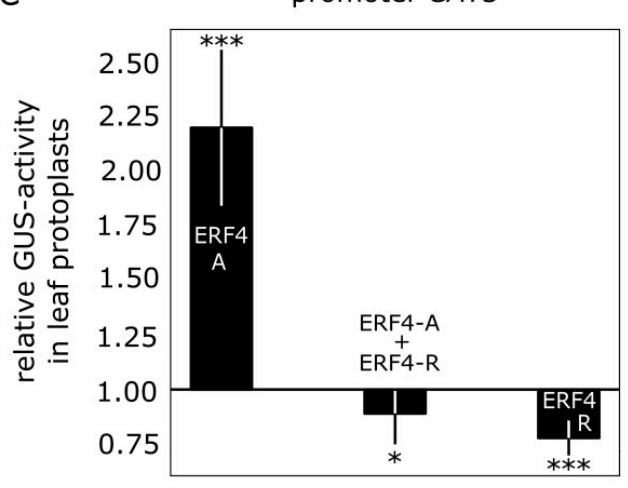

D CAT3 enzyme activity
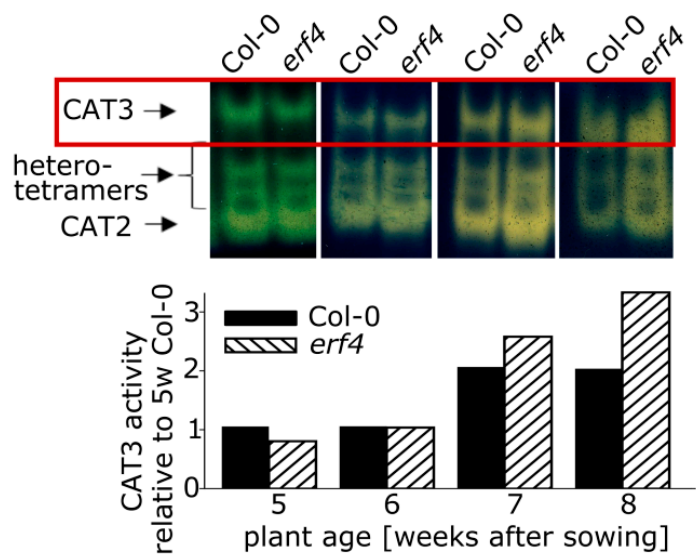

Figure 5. ERF4 binds to the CATALASE3 promoter and can act as activator and repressor. (A) Schematic representation of the CAT3 promoter fragments used for $\mathrm{Y} 1 \mathrm{H}$ screen and for DPI-ELISA. (B) DPI-ELISA using bacterial crude extracts of E. coli BL21 Rosetta cells expressing 6xHis-ERF4-A, 6xHis-ERF4-R or the empty vector and a 55-bp biotinylated DNA fragment of the CAT3 promoter, which contains the DRE motif CAGCC. Representative wells of the micro titer plate are shown below the graph. Yellow color indicates interaction. Error bars indicate $\pm \mathrm{SE}, n=4-5$. (C) Transient expression assays were performed using the $1.8 \mathrm{kbp}$ fragment of the CAT3 promoter upstream of the start codon in Arabidopsis Col-0 and erf4 leaf protoplasts. Values represent fold-change of GUS-activity relative to the empty vector after normalization to luciferase activity to compensate for differences in transformation efficiency. Data are means of seven experiments $(n=7)$. Statistical differences were analyzed by one sample t-test $\left({ }^{*} p \leq 0.05,{ }^{* *} p \leq 0.005,{ }^{* * *} p \leq 0.0005\right)$. (D) Enzyme activity of catalase isoforms of Col-0 and erf4 mutant plants is visualized on a zymogram. Protein crude extract $(10 \mu \mathrm{g})$ of leaf No. 6 of 5- to 8-week-old plants were separated on $7.5 \%$ native gels and stained for catalase activity. Proteins were extracted of a pool of at least 10 leaves. Intensities of the CAT3 bands were quantified using ImageJ.

To analyze the effect of ERF4 isoforms on the expression of CAT3 in vivo, transient co-transformations of a $1.8 \mathrm{kbp}$ CAT3-promoter:GUS construct along with 35S:ERF4-R or 35S:ERF4- $A$ overexpression constructs in Arabidopsis Col-0 or erf4 protoplasts were analyzed for GUS protein 
expression (Figure 5C). Protein formation of ERF4-R and ERF4-A was identified in the transformed protoplasts by immunodetection (Figure S6). Reporter gene expression was repressed by the overexpression of ERF4- $R$ as expected for a direct target gene of a protein containing an EAR motif, whereas overexpression of ERF4- $A$ resulted in an increased reporter gene activity (Figure 5C). This clearly suggests that the isoforms have an antagonistic function in the regulation of $C A T 3$. Simultaneous co-transformation of both isoforms led to reporter gene repression (Figure 5C) suggesting that the repressor isoform is dominant over the activator form.

CAT3 protein amount and activity increases during development and progression of senescence in wildtype plants (Figure S5A,B; [7,42]). When the activity of the catalase isoforms was analyzed by zymograms in Col-0 and erf4 mutant plants during plant development, a peculiar activity pattern could be observed for CAT3. As band intensities on catalase zymograms are proportional to enzyme activity in a wide range [7], CAT3 activity was quantified using ImageJ. In 5-week-old plants, CAT3 activity was lower in erf4 leaves compared to leaves of Col-0 plants, which is more obvious in the growth series shown in Figure S5, most likely due to slightly different velocities in development of different growth series. In 6-week-old plants, CAT3 activity was equal in erf4 plants compared to wildtype and in 7- and 8-week-old plants CAT3 activity is higher than in Col-0 plants (Figure 5D; Figure S5B). This suggests that the loss of ERF4 has an age-dependent influence on CAT3 activity: at early stages the activator ERF4-A appears to have a higher impact whereas at later stages of development the repressor ERF-R has a dominant effect.

\subsection{ERF4 Isoforms Form Homo- and Heterodimers, but Homodimers are Less Favored}

The existence of the two different isoforms raised the question, whether or not they form homoand/or heterodimers. Therefore, we first analyzed the formation of different dimers in vitro by a pull-down of recombinant proteins via Ni-agarose-beads. E. coli BL21 Rosetta cells were transformed with constructs coding for N-terminal GST-tagged and N-terminal 6xHIS-tagged fusion proteins (Figure 6A). GST-ERF4-A and GST-ERF4-R could be successfully pulled down with both HIS-ERF4-A and HIS-ERF4-R proteins. These results demonstrate that in vitro both the formation of homo- and heterodimers is possible.

To confirm the dimerization in planta, bimolecular fluorescence complementation (BiFC) combined with flow cytometry was performed. Arabidopsis Col-0 protoplasts were transformed with constructs coding for the sequences of ERF4- $A$ and ERF4-R, which were N-terminally fused to the sequences coding for the $\mathrm{N}$ - and C-terminal part of eYFP, respectively. As positive control WRKY53 constructs were included, since WRKY53 proteins are already shown to form homodimers [23]. Flow cytometry results show that homodimers of both ERF4 isoforms could be formed with the same probability as WRKY53 homodimers (Figure 6B,C and Figure S7A). In contrast to the pull-down experiments, heterodimers between both ERF4 isoforms and with WRKY53 are-if at all—formed with a much lower probability. They are not significantly different from the background signals of the mRFP control. Under the confocal laser-scanning microscope, the YFP signal of the BiFC is predominantly localized in the nucleus (Figure S7B). 


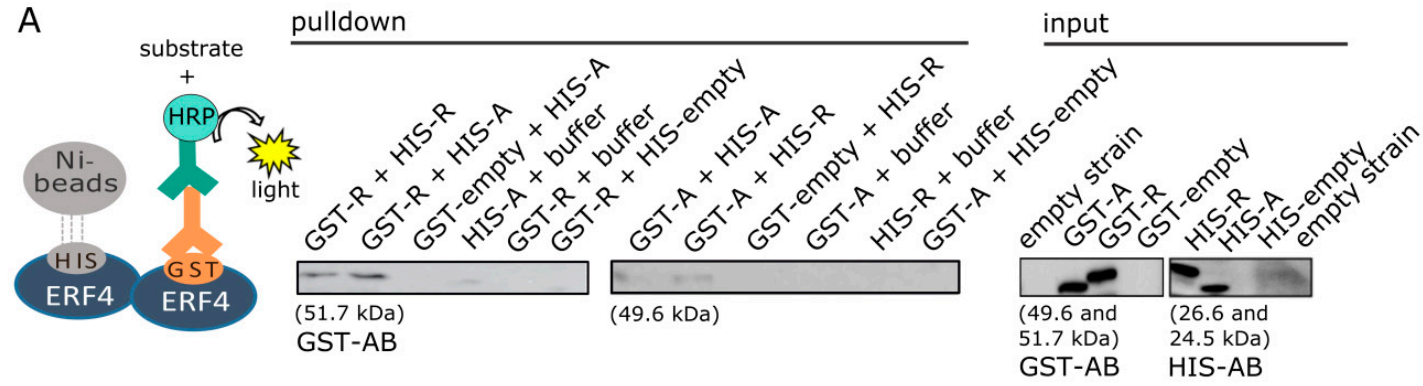

B

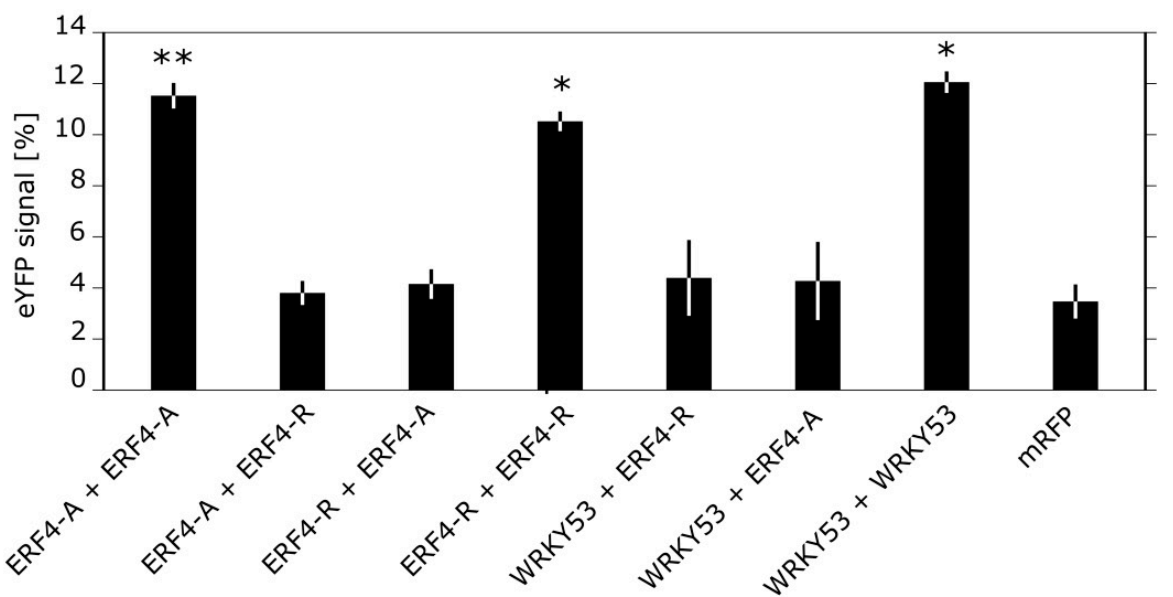

C ERF4-R with ERF4-R

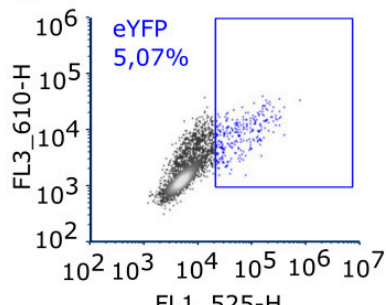

ERF4-A with ERF4-A
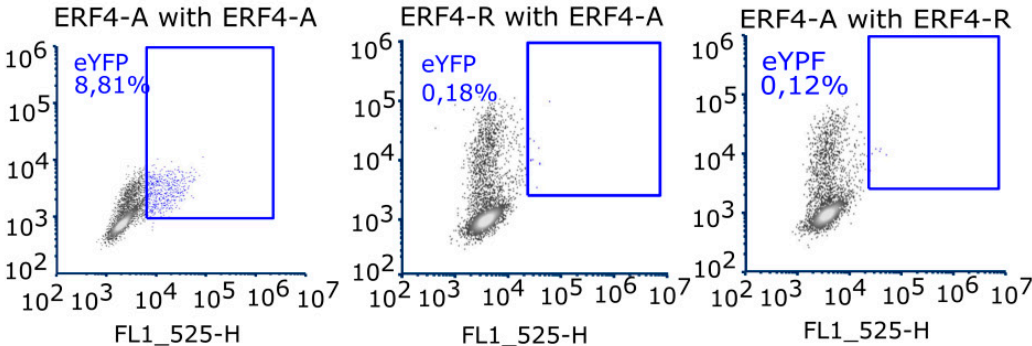

Figure 6. Protein-protein interaction of ERF4-A and ERF4-R.(A) Pull-down assay was performed using total protein extracts from E. coli BL21 Rosetta cells. GST-tagged ERF4-R (51.7 kDa) and ERF4-A (49.6 kDa) was pulled down with HIS-tagged ERF4-R (26.6 kDa) and ERF4-A (24.5 kDa) proteins and immunodetected with anti-GST antibodies. The input protein $(25 \mu \mathrm{g})$ was visualized with anti-GST and anti-HIS antibodies. The experiment shown was performed three times with similar results. (B) BiFC flow cytometry experiments were performed in Arabidopsis protoplasts co-expressing ERF4-R and ERF4-A fused with YFP-N and YFP-C, respectively. YFP-N fusion with WRKY53 and YFP-C fusions with both ERF4 isoforms were used as negative controls and YFP-N and YFP-C fusions with WRKY53 as positive control. RFP is expressed as transfection control. Bars represent percentage of cells with eYFP signal (mean values ( \pm SE), $n=7$ for combinations with ERF4 isoforms, $n=3$ for combinations with WRKY53). Data was subjected to quantile normalization and determination of statistical differences was carried out using Wilcoxon rank sum test $\left({ }^{*} p \leq 0.05,{ }^{* *} p \leq 0.005\right)$. (C) Representative graphs of the flow cytometry results for ERF4 homodimers and heterodimers. Blue dots represent eYFP signals of interaction. Blue squares mark the cells showing eYFP signal.

\subsection{FPA Inhibits ERF4-A Formation and Appears to be Involved in Senescence Regulation}

Lyons and coworkers observed that the RNA-binding protein FPA inhibits the formation of the ERF4-A form by promoting the polyadenylation in favor of the ERF4-R form [27]. We could show by qRT-PCR that FPA exhibited a senescence-specific expression pattern with rising expression levels in older plants (Figure 7A) that coincide with a decrease in ERF4A/ERF4R ratio (Figure 7B). In erf4 
plants, the increase of FPA expression is delayed most likely due to the delayed senescence of erf4. Furthermore, sqRT-PCR confirmed that ERF4- $A$ accumulates to much higher expression levels in fpa mutant plants (Figure 7C) as observed previously by Lyons et al. [27]. Therefore, we wanted to analyze whether FPA also has an influence on leaf senescence and therefore characterized two fpa T-DNA insertion lines (SAIL 849-F10 and SAIL 720-B10) in that regard. Each T-DNA insertion was confirmed by PCR. As FPA also controls flowering by repressing FLOWERING LOCUS C expression, the mutant plants have a strong delay in bolting and flowering. The shoot apical meristem (SAM) developed 30 and 40 leaves before the plant started bolting, as compared to Col-0, which had around 13 leaves (Figure 7D). Therefore, senescence phenotyping is very difficult as ideally plants of the same developmental stage should be compared. Nevertheless, with regard to the first 13 leaves, fpa mutants displayed accelerated senescence (Figure 7E) possibly indicating that FPA is not only involved in regulation of flowering time but also in senescence.

A

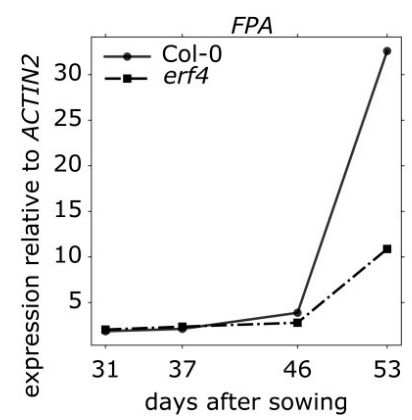

B

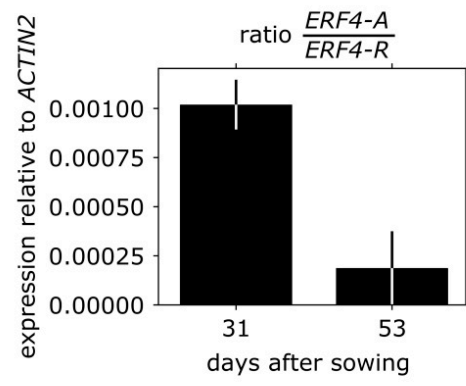

C

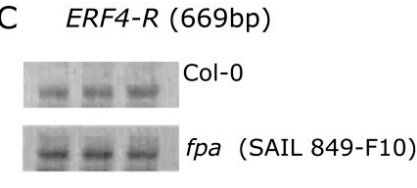

ERF4-A (771 bp)

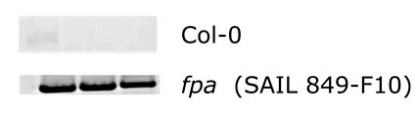

D

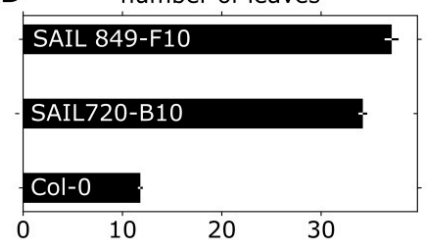

E SAIL 849-F10
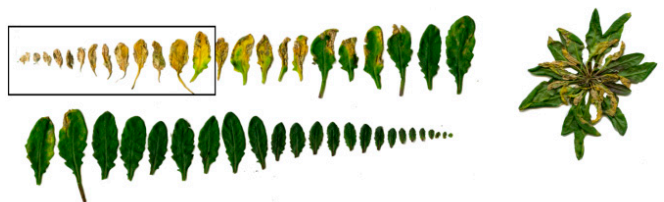

SAIL 720-B10

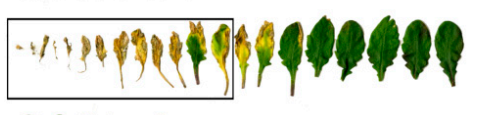

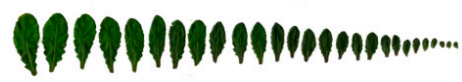

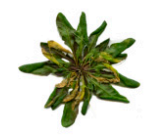

Col-0

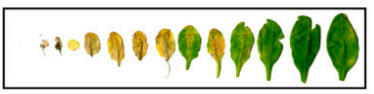

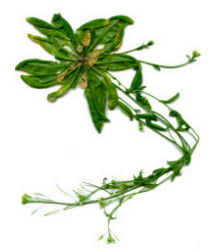

Figure 7. Characterization of fpa plants. (A) qRT-PCR data shows expression level of FPA in Col-0 and erf4 plants relative to ACTIN2. Leaves No. 7 of 5 biological replicates were pooled. Data are means of two technical replicates. (B) Ratio between ERF4- $A$ and ERF4- $R$ mRNAs at early (31 DAS) and late stages of development (51 DAS) (C) Semi-quantitative-PCR (sqRT-PCR) with RNA isolated from a pool of 10 plants was performed. Images show representative bands on a $1 \%$ agarose gel for ERF4-R (27 cycles, $2 \mu \mathrm{L}$ cDNA, $669 \mathrm{bp}$ ) and ERF4- $A$ ( 36 cycles, $3 \mu \mathrm{L}$ cDNA, $771 \mathrm{bp}$ ) in Col-0 and fpa (SAIL 849-F10) plants of three technical replicates. (D) Number of rosette leaves 6 weeks (42 DAS) after sowing of fpa and Col-0 plants. Error bars indicate $\pm \mathrm{SE}, n=10$. (E) Representative pictures of rosette leaves sorted according to their age 7.5 weeks (51 DAS) after sowing of two fpa lines (SAIL 849-F10 and SAIL 720-B10) and Col-0. 


\section{Discussion}

Leaf senescence goes along with massive changes in gene expression [12] and transcription factors play a key role in the differential expression of genes. Class II ERFs are transcription factors involved in many different processes and signaling pathways. They participate in the responses to pathogen, ethylene, SA, JA, auxin, salt and ABA [43-48]. Moreover, they are involved in cell death and senescence processes. For example, NbCD1, a Nicotiana benthamiana class II ERF, has been characterized to positively regulate cell death [49] and the AP2/ERF factor MACD1 as well as ERF102 were also reported to be involved in phytotoxin-triggered programmed cell death in Nicotiana umbratica [50]. Furthermore, NtERF3 and other ERFs containing the EAR motif of tobacco or rice were able to induce hypersensitive response (HR) when overexpressed in plants [51]. Koyama and coworkers [17] identified a regulatory cascade involving Arabidopsis ERF4 and ERF8 to promote leaf senescence. Even though the growth regulator ethylene is part of its name, responsiveness to this phytohormone is not a collective feature of all ERFs. Moreover, ERFs can have dual functions, as for example ERF-VII proteins act as positive regulators of the hypoxic response and as repressors of oxidative-stress related genes, depending on the developmental stage of the $A$. thaliana plants [52]. In this study, we expand the context and/or age-dependent function of ERFs to ERF4 of Arabidopsis and describe the role of two ERF4 isoforms derived from alternative polyadenylation in senescence. Phenotyping experiments show that both isoforms have a different and opposing impact on senescence: whereas 35S:ERF4-R plants show an accelerated phenotype, 35S:ERF4- $A$ plants are slightly delayed in leaf senescence (Figure 1A-F). Complementation of the ERF4 loss in erf4 mutant plants indicated that both isoforms were able to complement the delayed senescence of erf4 with a tendency of ERF4-A to restore the wildtype phenotype slightly better (Figure 3A-E). This indicates that ERF4-A and ERF4-R both contribute to the senescence regulatory effect of ERF4 having partially overlapping functions and that alternative polyadenylation is part of the regulatory network of senescence. Nevertheless, it was unexpected that both isoforms were able to complement the mutant phenotype since both isoforms exhibit opposing effects on the expression of the direct target gene CAT3 (Figure 5C) and PDF1.2 [27]. However, WRKY53 expression was affected in the same direction by both isoforms, either directly or indirectly. Microarray analyses of the ERF4-R overexpressing line revealed that not only WRKY53 but also many other WRKY transcription factors are downstream targets of ERF4 [17] and many of those are involved in senescence regulation. Moreover, WRKYs act in a transcriptional network influencing the expression of each other so that the outcome on senescence can hardly be predicted [21,23]. On the other hand, single knock-out mutants of transcription factors involved in senescence regulation often do not show any obvious phenotype even though they are responsible for changes in the transcriptome. These changes in gene expression are contributing to the senescence process as a whole but do not necessarily relate to a visible phenotype. Therefore, complementing only one of the two isoforms might be sufficient to restore the phenotype even though the absence of the other still leads to changes in senescence-associated genes (SAG) expression, which could explain that both isoforms were able to complement the mutant phenotype. Therefore, a general transcriptome analysis of the complementation lines will be subject of further investigations and will give insight in differential changes to identify specific target genes of either isoform. Both complementation lines performed slightly different in complementing the mutant: ERF4-A appears to be more important at earlier stages of senescence and more involved in regulating intracellular $\mathrm{H}_{2} \mathrm{O}_{2}$ concentration (Figure 3C) whereas ERF4-R appears to promote membrane integrity (Figure 3E). Therefore, it can be assumed that different and specific target genes and pathways are targeted by the different isoforms. The simultaneous presence of the two opposing isoforms render in planta function of ERF4 very complex. The total amount of the ERF4 mRNA increases with age and both isoforms can be detected in leaves throughout development from 31-46 DAS. However, the ratio between the mRNAs of the two isoforms changes over development. The ERF4- $A$ form is always less abundant than the ERF4- $R$ form, but at 31 DAS the A:R ratio is highest (Figure $2 \mathrm{C}$ ). To counterbalance the low abundance of the $E R F-A$ mRNA, the resulting ERF-A protein is more stable than the ERF4-R protein (Figure 2D). 
The formation of the ERF4- $A$ form was shown to be dependent on FPA, a RNA-binding protein, which inhibits the alternative polyadenylation [27]. Expression of $F P A$ is dependent on plant age and increases with senescence (Figure 7A). Consistent with this increase, the ratio between ERF4- $A$ and ERF4-R is lower at a later time point (Figure 7B). This increase in FPA expression is less pronounced in erf4 mutant plants (Figure 7A) due to either delayed senescence or a feedback regulation of ERF4 on FPA. As FPA also controls flowering by repressing FLOWERING LOCUS C expression, the mutants have a strong delay in bolting and flowering. Therefore, it is difficult to compare senescence with Col-0 plants, as, in general, plants of the same developmental stage should be compared. Whereas Col-0 plants developed only 13 leaves and had already flowers and siliques, fpa mutants continued to produce more than 30 leaves without bolting and flowering. However, if the first 13 leaves of plants with the same age are compared, fpa mutants might be accelerated in senescence in these leaves. As fpa plants have higher amounts of ERF4-A (Figure 7C), the phenotype should resemble the 35S:ERF4- $A$ overexpressing line. However, this line shows only a slightly accelerated senescence at $41 \mathrm{DAS}$, and at later time points it appears to be slightly delayed, indicating that this needs further investigations and that FPA is most likely involved in the regulation of polyadenylation of more target genes. Remarkably, FPA is involved in the regulation of two processes, which show overlapping gene expression patterns with senescence, namely flowering and pathogen response. This suggests that alternative polyadenylation is another mean for the cross-talk between these three processes.

We identified ERF4 as a DNA-binding protein of the CAT3 promoter in an Y1H screen (Figure 5A). Some members of the ERF family have been shown to bind in vitro to an AGCCGCC motif (GCC-box) [53], while other ERFs have also been reported to bind DRE elements [41], or even novel DNA elements [54,55]. We confirmed the in vitro binding of both protein isoforms ERF4-R and ERF4-A to the CAT3 promoter to a fragment containing the DRE motif with DPI-ELISA (Figure 5B). Reporter gene assays revealed that ERF4-R containing the EAR motif always had a repressing effect on reporter gene expression controlled by the CAT3 promoter, whereas ERF4-A lacking the EAR motif activated CAT3 driven reporter gene expression in leaf protoplasts (Figure 5C). The ERF4 gene also contains a conserved motif with high number of acidic residues, which might function as activating domain in the absence of the EAR motif (Figure S8). Our results are consistent with that of Lyons and coworkers [27] who could also show the transcriptional activation of ERF4-A on a GAL4-GCC promoter and the PDF1.2 expression. Co-transformation of both effectors led to a repression (Figure 5C). Therefore, ERF4-A can activate CAT3 expression but, when both isoforms compete with each other, it appears to be less efficient.

CAT3 is an interesting target gene for a senescence-regulating transcription factor, as catalases control $\mathrm{H}_{2} \mathrm{O}_{2}$ levels, which have been shown to act as signaling molecules in senescence. In planta, CAT3 activity increased with senescence in Col-0 plants (Figure 5D, Figure S5B). In contrast, a complex activity pattern became obvious in the erf4 mutant. In younger plants, activity is lower compared to wildtype indicating the loss of a CAT3 activating factor, whereas in older plants CAT3 activity is higher compared to Col-0 plants pointing at the loss of a repressing factor. This suggests that the ERF4-A isoform has its highest impact at an early time point of senescence, whereas ERF4-R is more important at later stages. This is consistent with the inhibition of ERF4-A formation by FPA in later stages (Figure 7A-C). All three catalases in Arabidopsis display a senescence-associated activity pattern, in which CAT2 is downregulated during early senescence, CAT3 is upregulated during progression of senescence and $C A T 1$ is upregulated during late senescence. A fine-tuned regulatory loop between CAT2, CAT3, and ASCORBATE PEROXIDASE1 activities leads to an early peaking of $\mathrm{H}_{2} \mathrm{O}_{2}$ in senescence, which is used as a signal to induce senescence-associated gene expression $[7,56]$. Moreover, activity of many transcription factors is directly controlled by redox conditions [57]. Therefore, ERF4 could affect senescence progression also via its impact on the signaling molecule $\mathrm{H}_{2} \mathrm{O}_{2}$ through activation or repression of CAT3. CAT3 expression is in general induced by high levels of $\mathrm{H}_{2} \mathrm{O}_{2}$; however, during progression of senescence, this responsivity is specifically blocked while other stress responses are still working [58]. ERF4-R might be involved in the disruption of this 
substrate induction to guarantee an increase in ROS during senescence, which is important to induce $S A G$ expression and in later stages also for membrane deterioration and macromolecule breakdown.

Figure 8 illustrates our hypothesis of how ERF4 isoforms influence the progression of leaf senescence. ERF4 transcription rate increases with leaf age but due to increasing FPA levels in later stages of development the ratio between ERF4-A and ERF4-R forms is changed by alternative polyadenylation. In early stages, ERF4-A is enriched since FPA expression is low. At this time point ERF4-A positively influences the expression of $C A T 3$ and thereby keeps $\mathrm{H}_{2} \mathrm{O}_{2}$ levels low. With onset and progression of senescence, FPA levels increase and ERF4-A production is minimized. ERF4-R now negatively regulates CAT3 expression leading to an increase in $\mathrm{H}_{2} \mathrm{O}_{2}$ production. This increased intracellular $\mathrm{H}_{2} \mathrm{O}_{2}$ levels now induce the expression of the senescence regulator WRKY53 and many other senescence-associated transcription factors and SAGs.

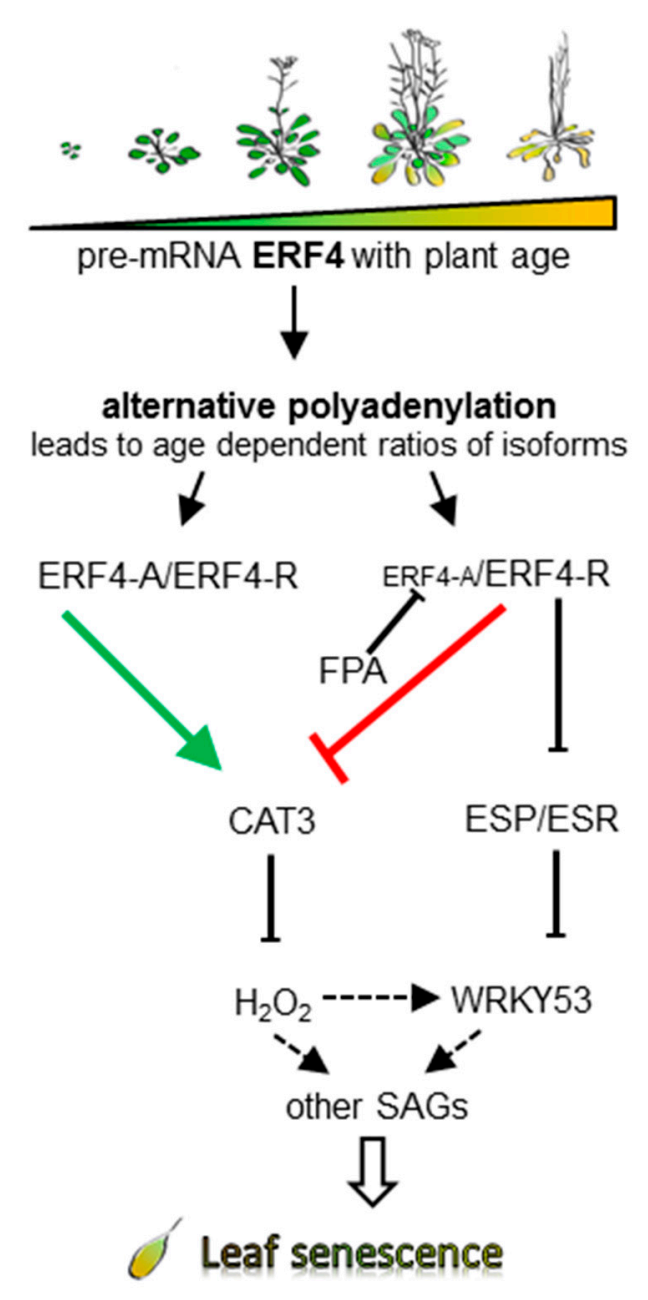

Figure 8. Model of the impact of the ERF4 isoforms in early and late senescence. Alternative polyadenylation, influenced by the RNA-binding protein FPA, leads to different ratios between the two isoforms in early and late senescence. FPA, which increases with age, leads to a reduced amount of ERF4-A in older plants, and consequently reduces the activation potential of ERF4-A on CAT3. Increasing $\mathrm{H}_{2} \mathrm{O}_{2}$ levels trigger expression of WRKY53 and other senescence-associated genes (SAGs) and thereby leaf senescence. ERF4-R acts as a negative regulator of CAT3 and ESP/ESR and thereby indirectly as a positive regulator of WRKY53 expression and activity.

Moreover, ERF4-R directly and negatively regulated the expression of ESP/ESR, which in turn is a negative regulator of WRKY53 expression and activity. However, WRKY53 appears to be upregulated by ERF4 also in an ESP/ESR-independent pathway (Figure 4), but it is still unknown, whether this is 
an indirect or direct regulation. The latter appears to be likely, since our in silico analyses identified at least four ethylene responsive cis-elements and a DRE element in the WRKY53 1000 bp upstream promoter region. Taken together, our findings reveal that ERF4-A and ERF4-R both contribute to the senescence regulatory effect of ERF4 and that alternative polyadenylation adds a further layer of complexity to the regulatory network of senescence.

Supplementary Materials: The following are available online at http:/ /www.mdpi.com/2073-4425/10/2/91/s1. Figure S1: Measurement of different parameters over the development of Col-0, 35S:ERF4-R, 35S:ERF4-A and erf4 mutant plant lines. Figure S2: Relative expression level of senescence-related genes. Figure S3: Isoform specific semi-quantitative RT-PCR. Figure S4: Isoform specific semi-quantitative RT-PCR of the complementation lines. Figure S5: CATALASE protein amounts and enzyme activity in 5- to 8- week-old Col-0 and erf4 mutant plants. Figure S6: ERF4-A and ERF4-R protein expression in Arabidopsis protoplasts. Figure S7: Protein-Protein interactions in transiently transformed protoplasts. Figure S8: Protein alignment of the first 122 amino acids (AA) of A. thaliana and N. tabacum ERF4. Table S1: Primer sequences.

Author Contributions: Conceptualization, U.Z. and L.R.; Methodology, L.R., J.D. and K.W.B.; Validation, L.R., S.K.-H., J.D. and K.W.B.; Formal Analysis, L.R.; Investigation, L.R., S.K.-H., J.D. and K.W.B.; Writing - Original Draft Preparation, L.R.; Writing - Review \& Editing, J.D.; K.W.B. and U.Z.; Visualization, L.R. and U.Z.; Supervision, U.Z. and J.D.; Project Administration, U.Z.; Funding Acquisition, U.Z.

Funding: This research was supported by the Deutsche Forschungsgemeinschaft (CRC 101, B06).

Acknowledgments: We greatly acknowledge Verena Kochan and Petra Müller (ZMBP, University of Tübingen) for providing the initial $\mathrm{Y} 1 \mathrm{H}$ data on CAT3 promoter fragments and data shown in Figure S5. We thank Gesine Seibold, Julian Fratte, Caterina Brancato and Manuela Freund for their technical support. We also thank Tobias Jachowski for programming the automated leaf segmentation tool for the ACA software. We are grateful to Koyama and coworkers as well as Lyons and coworkers for kindly providing seeds for the ERF4 overexpressing and complementation lines and J. Feierabend for providing the anti-rye-CAT antibody. Moreover, we thank Gero Hermsdorf and Steve Simmert for their advice and help in formatting plots in Python. Finally, we thank the Nottingham Arabidopsis Stock Center (NASC) for providing seeds SALK_073394, SAIL720_B10, SALK_011615, SAIL_849_F10, and SALK_055029C.

Conflicts of Interest: The authors declare no conflicts of interest.

\section{References}

1. Gan, S.; Amasino, R.M. Inhibition of leaf senescence by autoregulated production of cytokinin. Science 1995, 270, 1986-1988. [CrossRef] [PubMed]

2. Lim, P.O.; Kim, H.J.; Nam, H.G. Leaf Senescence. Annu. Rev. Plant Biol. 2007, 58, 115-136. [CrossRef] [PubMed]

3. Kim, J.; Kim, J.H.; Lyu, J.I.; Woo, H.R.; Lim, P.O. New insights into the regulation of leaf senescence in Arabidopsis. J. Exp. Bot. 2018, 69, 787-799. [CrossRef] [PubMed]

4. Buchanan-Wollaston, V.; Earl, S.; Harrison, E.; Mathas, E.; Navabpour, S.; Page, T.; Pink, D. The molecular analysis of leaf senescence-A genomics approach. Plant Biotechnol. J. 2003, 1, 3-22. [CrossRef]

5. Schildhauer, J.; Wiedemuth, K.; Humbeck, K. Supply of nitrogen can reverse senescence processes and affect expression of genes coding for plastidic glutamine synthetase and lysine-ketoglutarate reductase/saccharopine dehydrogenase. Plant Biol. 2008, 10 (Suppl. 1), 76-84. [CrossRef]

6. Møller, I.M.; Sweetlove, L.J. ROS signalling-Specificity is required. Trends Plant Sci. 2010, 15, 370-374. [CrossRef]

7. Zimmermann, P.; Heinlein, C.; Orendi, G.; Zentgraf, U. Senescence-specific regulation of catalases in Arabidopsis thaliana (L.) Heynh. Plant Cell Environ. 2006, 29, 1049-1060. [CrossRef]

8. Zimmermann, P.; Zentgraf, U. The correlation between oxidative stress and senescence during plant development. Cell. Mol. Biol. Lett. 2005, 10, 515-534.

9. Lin, J.F.; Wu, S.H. Molecular events in senescing Arabidopsis leaves. Plant J. 2004, 39, 612-628. [CrossRef]

10. Balazadeh, S.; Riaño-Pachón, D.M.; Mueller-Roeber, B. Transcription factors regulating leaf senescence in Arabidopsis thaliana. Plant Biol. 2008, 10 (Suppl. 1), 63-75. [CrossRef]

11. Buchanan-Wollaston, V.; Page, T.; Harrison, E.; Breeze, E.; Lim, P.O.; Nam, H.G.; Lin, J.F.; Wu, S.H.; Swidzinski, J.; Ishizaki, K.; et al. Comparative transcriptome analysis reveals significant differences in gene expression and signalling pathways between developmental and dark/starvation-induced senescence in Arabidopsis. Plant J. 2005, 42, 567-585. [CrossRef] [PubMed] 
12. Breeze, E.; Harrison, E.; McHattie, S.; Hughes, L.; Hickman, R.; Hill, C.; Kiddle, S.; Kim, Y.S.; Penfold, C.A.; Jenkins, D.; et al. High-resolution temporal profiling of transcripts during Arabidopsis leaf senescence reveals a distinct chronology of processes and regulation. Plant Cell 2011, 23, 873-894. [CrossRef]

13. Riechmann, J.L.; Heard, J.; Martin, G.; Reuber, L.; Jiang, C.; Keddie, J.; Adam, L.; Pineda, O.; Ratcliffe, O.J.; Samaha, R.R.; et al. Arabidopsis transcription factors: Genome-wide comparative analysis among Eukaryotes. Science 2000, 290, 2105-2110. [CrossRef] [PubMed]

14. Nakano, T.; Suzuki, K.; Fujimura, T.; Shinshi, H. Genome-wide analysis of the ERF gene family in Arabidopsis and rice. Plant Physiol. 2006, 140, 411-432. [CrossRef] [PubMed]

15. Licausi, F.; Ohme-Takagi, M.; Perata, P. APETALA2/ethylene responsive factor (AP2/ERF) transcription factors: Mediators of stress responses and developmental programs. New Phytol. 2013, 199, 639-649. [CrossRef] [PubMed]

16. Mizoi, J.; Shinozaki, K.; Yamaguchi-Shinozaki, K. AP2/ERF family transcription factors in plant abiotic stress responses. Biochim. Biophy. Acta 2012, 86-96. [CrossRef] [PubMed]

17. Koyama, T.; Nii, H.; Mitsuda, N.; Ohta, M.; Kitajima, S.; Ohme-Takagi, M.; Sato, F. A regulatory cascade involving class II ETHYLENE RESPONSE FACTOR transcriptional repressors operates in the progression of leaf senescence. Plant Physiol. 2013, 162, 991-1005. [CrossRef]

18. Miao, Y.; Zentgraf, U. The antagonist function of Arabidopsis WRKY53 and ESR/ESP in leaf senescence is modulated by the jasmonic and salicylic acid equilibrium. Plant Cell 2007, 19, 819-830. [CrossRef] [PubMed]

19. Miao, Y.; Laun, T.; Zimmermann, P.; Zentgraf, U. Targets of the WRKY53 transcription factor and its role during leaf senescence in Arabidopsis. Plant Mol. Biol. 2004, 55, 853-867. [CrossRef]

20. Ay, N.; Irmler, K.; Fischer, A.; Uhlemann, R.; Reuter, G.; Humbeck, K. Epigenetic programming via histone methylation at WRKY53 controls leaf senescence in Arabidopsis thaliana. Plant J. 2009, 58, 333-346. [CrossRef]

21. Zentgraf, U.; Laun, T.; Miao, Y. The complex regulation of WRKY53 during leaf senescence of Arabidopsis thaliana. Eur. J. Cell Biol. 2010, 89, 133-137. [CrossRef] [PubMed]

22. Xie, Y.; Huhn, K.; Brandt, R.; Potschin, M.; Bieker, S.; Straub, D.; Doll, J.; Drechsler, T.; Zentgraf, U.; Wenkel, S. REVOLUTA and WRKY53 connect early and late leaf development in Arabidopsis. Development 2014, 141, 4772-4783. [CrossRef] [PubMed]

23. Potschin, M.; Schlienger, S.; Bieker, S.; Zentgraf, U. Senescence networking: WRKY18 is an upstream regulator, a downstream target gene, and a protein interaction partner of WRKY53. J. Plant Growth Reg. 2014, 33, 106-118. [CrossRef]

24. Fujimoto, S.Y.; Ohta, M.; Usui, A.; Shinshi, H.; Ohme-Takagi, M. Arabidopsis ethylene-responsive element binding factors act as transcriptional activators or repressors of GCC box-mediated gene expression. Plant Cell 2000, 12, 393-404. [CrossRef] [PubMed]

25. Ohta, M.; Ohme-Takagi, M.; Shinshi, H. Three ethylene-responsive transcription factors in tobacco with distinct transactivation functions. Plant J. 2000, 22, 29-38. [CrossRef] [PubMed]

26. Ohta, M.; Matsui, K.; Hiratsu, K.; Shinshi, H.; Ohme-Takagi, M. Repression domains of class II ERF transcriptional repressors share an essential motif for active repression. Plant Cell 2001, 13, 1959-1968. [CrossRef] [PubMed]

27. Lyons, R.; Iwase, A.; Gänsewig, T.; Sherstnev, A.; Duc, C.; Barton, G.J.; Hanada, K.; Higuchi-Takeuchi, M.; Matsui, M.; Sugimoto, K.; et al. The RNA-binding protein FPA regulates flg22-triggered defense responses and transcription factor activity by alternative polyadenylation. Sci. Rep. 2013, 3, 2866. [CrossRef]

28. Barbazuk, W.B.; Fu, Y.; McGinnis, K.M. Genome-wide analyses of alternative splicing in plants: Opportunities and challenges. Genome Res. 2008, 18, 1381-1392. [CrossRef]

29. Li, Q.; Lin, Y.C.; Sun, Y.H.; Song, J.; Chen, H.; Zhang, X.H.; Sederoff, R.R.; Chiang, V.L. Splice variant of the SND1 transcription factor is a dominant negative of SND1 members and their regulation in Populus trichocarpa. Proc. Natl. Acad. Sci. USA 2012, 109, 14699-14704. [CrossRef]

30. Mastrangelo, A.M.; Marone, D.; Laidò, G.; De Leonardis, A.M.; De Vita, P. Alternative splicing: Enhancing ability to cope with stress via transcriptome plasticity. Plant Sci. 2012, 185-186, 40-49. [CrossRef]

31. Severing, E.I.; van Dijk, A.D.J.; Morabito, G.; Busscher-Lange, J.; Immink, R.G.H.; van Ham, R.C.H.J. Predicting the impact of alternative splicing on plant MADS domain protein function. PLOS ONE 2012, 7, e30524. [CrossRef] [PubMed] 
32. Slotte, T.; Huang, H.R.; Holm, K.; Ceplitis, A.; St. Onge, K.; Chen, J.; Lagercrantz, U.; Lascoux, M. Splicing variation at a FLOWERING LOCUS C homeolog is associated with flowering time variation in the tetraploid Capsella bursa-pastoris. Genetics 2009, 183, 337-345. [CrossRef] [PubMed]

33. Foyer, C.H.; Noctor, G. Oxygen processing in photosynthesis: Regulation and signalling. New Phytol. 2000, 146, 359-388. [CrossRef]

34. Mhamdi, A.; Queval, G.; Chaouch, S.; Vanderauwera, S.; Van Breusegem, F.; Noctor, G. Catalase function in plants: A focus on Arabidopsis mutants as stress-mimic models. J. Exp. Bot. 2010, 61, 4197-4220. [CrossRef] [PubMed]

35. Osterlund, M.T.; Hardtke, C.S.; Wei, N.; Deng, X.W. Targeted destabilization of HY5 during light-regulated development of Arabidopsis. Nature 2000, 405, 462-466. [CrossRef] [PubMed]

36. Mehlhorn, D.G.; Wallmerothm, N.; Berendzen, K.W.; Grefen, C. 2in1 vectors improve in planta BiFC and FRET analysis. Methods Mol. Biol. 2018, 691, 139-158.

37. Jefferson, R.A.; Kavanagh, T.A.; Bevan, M.W. GUS fusions: Beta-glucuronidase as a sensitive and versatile gene fusion marker in higher plants. Embo J. 1987, 6, 3901-3907. [CrossRef]

38. Grefen, C.; Blatt, M.R. A 2in1 cloning system enables ratiometric bimolecular fluorescence complementation (rBiFC). Biotechniques 2012, 53, 311-314. [CrossRef]

39. Bresson, J.; Bieker, S.; Riester, L.; Doll, J.; Zentgraf, U. A guideline for leaf senescence analyses: From quantification to physiological and molecular investigations. J. Exp.Bot. 2018, 69, 769-786. [CrossRef]

40. Pfaffl, M.W. A new mathematical model for relative quantification in real-time RT-PCR. Nucleic Acids Res. 2001, 29, 45e. [CrossRef]

41. Yang, S.; Wang, S.; Liu, X.; Yu, Y.; Yue, L.; Wang, X.; Hao, D. Four divergent Arabidopsis ethylene-responsive element-binding factor domains bind to a target DNA motif with a universal CG step core recognition and different flanking bases preference. FEBS J. 2009, 276, 7177-7186. [CrossRef] [PubMed]

42. Oñate-Sánchez, L.; Anderson, J.P.; Young, J.; Singh, K.B. AtERF14, a Member of the ERF family of transcription factors, plays a nonredundant role in plant defense. Plant Physiol. 2006, 143, 400-409. [CrossRef] [PubMed]

43. Ma, R.; Xiao, Y.; Lv, Z.; Tan, H.; Chen, R.; Li, Q.; Chen, J.; Wang, Y.; Yin, J.; Zhang, L.; et al. AP2/ERF Transcription Factor, Ii049, positively regulates lignan biosynthesis in Isatis indigotica through activating salicylic acid signaling and lignan/lignin pathway genes. Front. Plant Sci. 2017, 8, 1361. [CrossRef] [PubMed]

44. Eysholdt-Derzso, E.; Sauter, M. Root bending is antagonistically affected by hypoxia and ERF-mediated transcription via auxin signaling. Plant Physiol. 2017, 175, 412-423. [CrossRef] [PubMed]

45. Catinot, J.; Huang, J.B.; Huang, P.Y.; Tseng, M.Y.; Chen, Y.L.; Gu, S.Y.; Lo, W.S.; Wang, L.C.; Chen, Y.R.; Zimmerli, L. ETHYLENE RESPONSE FACTOR 96 positively regulates Arabidopsis resistance to necrotrophic pathogens by direct binding to GCC elements of jasmonate-And ethylene-responsive defence genes. Plant Cell Environ. 2015, 38, 2721-2734. [CrossRef] [PubMed]

46. Wang, X.; Liu, S.; Tian, H.; Wang, S.; Chen, J.G. The Small Ethylene Response Factor ERF96 is involved in the regulation of the abscisic acid response in Arabidopsis. Front. Plant Sci. 2015, 6, 1064. [CrossRef] [PubMed]

47. Zhang, L.; Li, Z.; Quan, R.; Li, G.; Wang, R.; Huang, R. An AP2 Domain-Containing Gene, ESE1, targeted by the ethylene signaling component EIN3 is important for the salt response in Arabidopsis. Plant Physiol. 2011, 157, 854-865. [CrossRef] [PubMed]

48. Nasir, K.H.; Takahashi, Y.; Ito, A.; Saitoh, H.; Matsumura, H.; Kanzaki, H.; Shimizu, T.; Ito, M.; Fujisawa, S.; Sharma, P.C.; et al. High-throughput in planta expression screening identifies a class II ethylene-responsive element binding factor-like protein that regulates plant cell death and non-host resistance. Plant J. 2005, 43, 491-505. [CrossRef] [PubMed]

49. Mase, K.; Ishihama, N.; Mori, H.; Takahashi, H.; Kaminaka, H.; Kodama, M.; Yoshioka, H. Transcription factor MACD1 participates in phytotoxin-triggered programmed cell death. Mol. Plant-Microbe Interact. 2013, 26, 868-879. [CrossRef] [PubMed]

50. Ogata, T.; Kida, Y.; Arai, T.; Kishi, Y.; Manago, Y.; Murai, M.; Matsushita, Y. Overexpression of tobacco ethylene response factor NtERF3 gene and its homologues from tobacco and rice induces hypersensitive response-like cell death in tobacco. J. Gen. Plant Pathol. 2012, 78, 8-17. [CrossRef]

51. Giuntoli, B.; Shukla, V.; Maggiorelli, F.; Giorgi, F.M.; Lombardi, L.; Perata, P.; Licausi, F. Age-dependent regulation of ERF-VII transcription factor activity in Arabidopsis thaliana. Plant Cell Environ. 2017, 40, 2333-2346. [CrossRef] [PubMed] 
52. Hao, D.; Ohme-Takagi, M.; Sarai, A. Unique mode of GCC Box Recognition by the DNA-binding Domain of Ethylene-responsive Element-binding Factor (ERF domain) in plant. J. Biol. Chem. 1998, 273, 26857-26861. [CrossRef] [PubMed]

53. Welsch, R.; Maass, D.; Voegel, T.; Dellapenna, D.; Beyer, P. Transcription factor RAP2.2 and its interacting partner SINAT2: Stable elements in the carotenogenesis of Arabidopsis leaves. Plant Physiol. 2007, 145, 1073-1085. [CrossRef] [PubMed]

54. Shaikhali, J.; Heiber, I.; Seidel, T.; Ströher, E.; Hiltscher, H.; Birkmann, S.; Dietz, K.J.; Baier, M. The redox-sensitive transcription factor Rap2.4a controls nuclear expression of 2-Cys peroxiredoxin A and other chloroplast antioxidant enzymes. BMC Plant Biol. 2008, 8, 48. [CrossRef]

55. Bieker, S.; Riester, L.; Stahl, M.; Franzaring, J.; Zentgraf, U. Senescence-specific alteration of hydrogen peroxide levels in Arabidopsis thaliana and oilseed rape spring variety Brassica napus L. cv. Mozart. J. Intgr. Plant Biol. 2012, 54, 540-554. [CrossRef] [PubMed]

56. He, H.; Van Breusegem, F.; Mhamdi, A. Redox-dependent control of nuclear transcription in plants. J. Exp. Bot. 2018, 69, 359-3372. [CrossRef] [PubMed]

57. Orendi, G.; Zimmermann, P.; Baar, C.; Zentgraf, U. Loss of stress-induced expression of catalase3 during leaf senescence in Arabidopsis thaliana is restricted to oxidative stress. Plant Sci. 2001, 161, 301-314. [CrossRef]

58. Hertwig, B.; Streb, P.; Feierabend, J. Light dependence of catalase synthesis and degradation in leaves and the influence of interfering stress conditions. Plant Physiol. 1992, 100, 1547-1553. [CrossRef]

(C) 2019 by the authors. Licensee MDPI, Basel, Switzerland. This article is an open access article distributed under the terms and conditions of the Creative Commons Attribution (CC BY) license (http://creativecommons.org/licenses/by/4.0/). 